\title{
MULTIPLE SOCIAL CATEGORIZATION AND THE PERCEPTION OF MULTIPLE SOCIAL IDENTITIES THROUGH THE \\ LENS OF INTERSECTIONALITY
}

\begin{abstract}
A Dissertation
Submitted

to the Temple University Graduate Board

In Partial Fulfillment

of the Requirements for the Degree of

Doctor of Philosophy
\end{abstract}

\author{
By \\ Amanda B. Breen \\ August, 2010
}

Examining Committee Members:

Andrew Karpinski, Advisory Chair, Psychology

Kareem Johnson, Psychology

Marsha Weinraub, Psychology

Deborah Drabick, Psychology

Peter Marshall, Psychology

Ronald Taylor, Psychology 
(C)

Copyright

2010

by

Amanda B. Breen

All Rights Reserved 


\begin{abstract}
Intersectionality theory can provide a useful research tool for social psychologists studying multiple social identities and social categorization. The overarching goal of this set of studies was to test the theory of intersectionality by investigating the perception of multiple social identities and category activation using quantitative methods traditionally employed in social psychological research. Study 1's major finding was that intersecting social identities accounted for nearly twice the amount of variance in overall impression ratings than did singular identities. Specifically, Study 1 examined how different combinations of three social identities based on race, gender, and sexual orientation differentially affected evaluation of overall impression and personality ratings. Different combinations of target race, target gender, and target sexual orientation affected overall impression ratings and personality ratings of honesty, emotionality, and openness. Notably, the combination of these social identities did not differentially affect personality ratings of extraversion, agreeableness, and conscientiousness. The goal of Study 2 was to investigate the possibility of simultaneous category activation, but did not yield significant results and therefore did not provide support for intersectionality theory. In Study 2, participants were primed with race, gender, or race and gender combined, and they subsequently completed a lexical decision task to measure category accessibility. There were no significant differences in mean lexical decision latencies by condition, indicating that the priming technique employed in this study was not effective. Implications and future directions for using intersectionality theory in psychological research are discussed.
\end{abstract}




\section{ACKNOWLEDGMENTS}

I never could have accomplished all that I have without my parents' unwavering support. Thank you for always believing in me even when you had no idea what I was doing (or why). To Andy Karpinski, you taught me to follow my research interests unabashedly. To Marsha Weinraub, you challenged me to think deeply about my work unlike anyone else. To the rest of my committee members, thank you very much for all of your thoughtful comments and support. My dissertation data never would have been collected without the dedication from my undergraduate research assistants: Amy Bauer, Aubrey Meyers, and Suchita Palit. To my love, I am indebted to you for all of your support, companionship, and humor throughout this process. 
To all the rockin' social psychologists who challenged the status quo and enabled me to pursue my research interests. 


\section{LIST OF TABLES}

Table

Page

1. Main Effects and Interaction Term Effects by Condition.................................. 77

2. Means and Standard Deviations of Target Ratings by Condition...................... 78

3. Study 1: Mean Target Ratings and Standard Deviations by Participant

Race and Target Race

4. Study 1: Mean Target Ratings and Standard Deviations by Participant Gender and Target Gender........................................................................ 80

5. Study 2: Mean Lexical Decision Latencies in Milliseconds as a Function of Prime and Trait Stereotypicality 


\section{LIST OF FIGURES}

Figure

Page

1. Study 1: Mean Ratings of Openness by Participant Gender and Target Gender......... 82 
ABSTRACT. iii



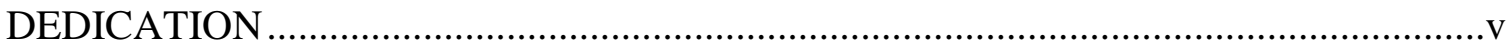



LIST OF FIGURES …………………......................................................... vii

CHAPTER

1. INTRODUCTION AND INTERSECTIONALITY ..............................................

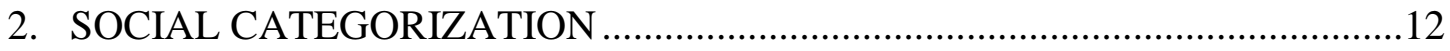

3. STUDY 1: INTERSECTIONALITY AND PERSON PERCEPTION ...................24

4. STUDY 2: INTERSECTIONALITY AND MULTIPLE CATEGORY



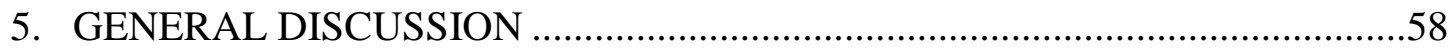

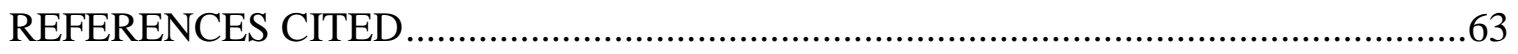

APPENDICES

A. STUDY 1: HOUSING AND RESIDENCE LIFE ROOMMATE SURVEY .........84

B. STUDY 1: HEXACO PERSONALITY INVENTORY ITEMS .............................87

C. STUDY 2: EXAMPLE OF SCHOLARSHIP APPLICATION FOR

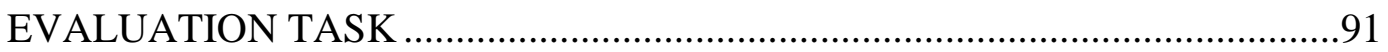

D. STUDY 2: SCHOLARSHIP APPLICATION EVALUATION

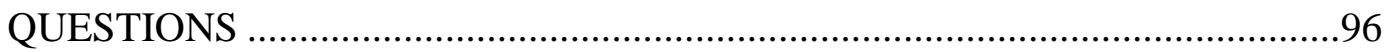

E. STUDY 2: STEREOTYPICALITY RATINGS USED IN PILOT STUDY ........97 


\section{CHAPTER 1}

\section{INTRODUCTION AND INTERSECTIONALITY}

"There's always someone asking you to underline one piece of yourself - whether it's Black, woman, mother, dyke, teacher, etc. - because that's the piece that they need to key in to. They want to dismiss everything else" (Lorde, 1981, p. 717). Audre Lorde's statement exemplifies both the complexity of human identity and the tendency for others to reduce that complexity in order to make sense of their social worlds in a cognitively efficient manner. However, despite "want[ing] to dismiss everything else," social perceivers do not always do so. As social perceivers, human beings categorize others almost automatically in order to gain rich information with little cognitive effort. In some instances only one category will be activated and used to influence perceptions, while in other situations multiple social categories may be activated in the social perception.

The ability to shift the degree and scope of category activation emphasizes the cognitive flexibility of human beings as social perceivers. While cognitive flexibility has its benefits, a constant tension exists between perceiving others as individuals and perceiving others based on their group membership(s). Social categorization research reflects this tension and provides evidence for social psychologists' growing acknowledgement of the complexity of social categorization. Acknowledging the possibility of multiple social categorization has moved the field closer to understanding the complexity of human identity and experience. However, little empirical research has directly tested how multiple social categories are cognitively processed. The theory of 
intersectionality can provide a theoretical framework for gaining a broader understanding of identity through its emphasis on the social structural processes that affect how individuals' multiple social identities are experienced and perceived.

\section{Intersectionality}

Originally introduced by feminist and critical race theorists (Collins, 2000; Crenshaw, 1991; King, 1988), intersectionality is defined as the "interaction between one's many social identities and the influences of different social structures on the construction of these identities and relations between members of diverse social groups" (Stewart \& McDermott, 2004, p. 331). Intersectionality was most notably conceptualized by law scholar Kimberlé Crenshaw in her examination of the legal consequences of violence against women of color in the United States (Crenshaw, 1991). Around this same time, some psychologists noted how the mainstream psychological literature on social identity could benefit from a focus on multiple social identities because traditionally it has "rarely examined or acknowledged the multiple layers of diversity and identity and instead offer one-dimensional images of culturally diverse individuals" (Reynolds \& Pope, 1991, p. 174). While recognizing the utility of examining the separate effects of identities, they urged that a greater focus be placed upon the multiplicity of identity, especially among individuals with more than one subordinated identity. Since then, the theory of intersectionality has been applied to an array of topics in fields as diverse as criminology (Burgess-Proctor, 2006), public health (Chong, Um, Hahn, Pheng, Yee, \& Auerswald, 2009), education (Gosse, Parr, \& Allison, 2008), social work (Hulko, 2009), and psychology. 
An upsurge of interest in using intersectionality as a research tool in psychology has occurred recently (e.g., Bowleg, 2008; Cole, 2009; McCall, 2005; Steinbugler, Press, \& Johnson Dias, 2006; Stewart \& McDermott, 2004; Warner, 2008). Within the field of psychology, intersectionality has been used as the theoretical framework to empirically study political consciousness (Greenwood \& Christian, 2008), altruism (Mattis, Grayman, Cowie, Winston, Watson, \& Jackson, 2008), and attitudes toward abortion (Press \& Cole, 1999). In general, using an intersectional approach is important because it focuses research on traditionally understudied populations like women, racial and ethnic minorities, and individuals with disabilities. An intersectional approach to psychological research necessitates that psychologists bear in mind the following tenets: 1) all social groups are heterogeneous; 2) individuals' experiences are affected by the power dynamics within the social structures in which they are located; and 3) there are unique effects of identifying with more than one social group (Stewart \& McDermott, 2004).

The first tenet suggests that social groups should not be approached as though they are homogenous. As psychologists, we must recognize the differences within groups to gain a better understanding of individuals' experiences and perceptions. The second tenet notes that differential statuses are attached to different social categories, which affects how a social identity is experienced. Finally the third tenet states that within the matrix of intersecting hierarchies, there are specific locations that create a unique set of experiences that reflect the interlocking nature of multiple social identities. Some psychologists have interpreted this to mean that the relationship among one's multiple social identities is never additive (e.g., Bowleg, 2008; Warner, 2008). However, Cole (2009) suggested that psychologists should not limit their understanding of multiple 
social identities to an intersectional approach, as there are circumstances when multiple social identities are best understood separately. For instance, Gay \& Tate (1998) found that for black women who strongly identified both as "women" and as "blacks," their racial identity was more important than their gender identity in influencing their attitudes toward such political events as the Million Man March, the O.J. Simpson trial, and the nomination of Clarence Thomas to the U.S. Supreme Court.

Three recent articles offered guidance about conducting research in psychology using an intersectional approach (Bowleg, 2008; Cole, 2009; Warner, 2008). Intersectionality theory should not be reserved as a feminist or alternative approach to the study of psychology, as evidenced by its application toward a diverse range of psychological topics and its consideration in a journal aimed at the entire field of psychology (i.e., American Psychologist). While each of the authors of these articles offered a slightly different perspective on intersectionality's utility in psychological research, they echoed many of the same sentiments. All three authors emphasized that intersectionality can be used to inform the entire research process, from hypothesis generation to the operationalization of variables to the interpretation of data, and they make practical recommendations for how research in this vein might be conducted. Bowleg (2008) contexualized her recommendations about the application of intersectionality throughout the research process with a study that she and her colleagues conducted about black lesbians as the context. Cole (2009) outlined a series of three questions that can inform how each stage of the research process is conducted. Warner (2008) offered a best practices guide to conducting intersectionality research in 
psychology, positioning her recommendations in relation to social psychological literature on categorization and social identities.

A key component to understanding the complexity of social identities is to recognize and situate them in relation to the institutional, political, and societal structures that influence how they are experienced and perceived (Bowleg, 2008; Cole, 2009; Warner, 2008). Intersectionality theorists recognize that social identity is dynamic and complex and best understood as a social structural process (Warner, 2008). There are several consequences of viewing identity in such a way. The first consequence is that it helps researchers to see points of connection at the intersection of an individual's multiple social identities rather than conceptualizing them as separate entities. Secondly, by situating identities in relation to the social structures that affect and shape them, it also may be easier to see commonalities across individuals' experiences of different social identities. For instance, the experiences and perceptions of women's subordinate status in the US and Iran may differ greatly. However, intersectionality theory can highlight the commonalities of women's experiences based on their location within the hierarchical social structure in each country. At their core, social psychologists are behavioral pattern detectors. Intersectionality theory provides a theoretical framework for finding the patterns in individuals' behavior and identities by linking them to social structures. Finally, looking at how identities relate to one another on a structural level shifts the focus on identity from one that is simply descriptive to one that seeks to understand the processes influencing identity experience and perception. From this perspective, social identities can only be fully understood when proper consideration has been given to their associated status of privilege or subordination. Identities that are often associated with 
privilege include but are not limited to being male, white, heterosexual, and able-bodied. Subordinate identities may include being female, a person of color (e.g., African American, Asian American, Hispanic), homosexual, and disabled. Consideration of how social structures interact to affect experiences and perceptions of identities is important throughout the research process, but may be most critical in the interpretation of findings (Warner, 2008).

A common theme of the three articles is the inclusion criteria for category membership. All are concerned with the types of individuals included in particular categories, as well as how and why the decisions around their inclusion are made by researchers. Warner (2008) argued that different considerations must be made for master categories (like gender) and for emergent categories (those that occur with the consideration of multiple identities). A master category is one that encompasses many different identities, experiences, and social locations (McCall, 2005). It can be best thought of as the superordinate category under which emergent categories are placed. Thus, an emergent category is one that results from the intersection among various master categories. A major assumption of intersectionality is a "both/and approach" to social categories. That is, researchers must acknowledge and understand both emergent and master categories, as their meanings are mutually dependent upon one another. Warner (2008) stated that research taking a both/and approach "acknowledges the distinct master categories at the same time as she or he considers the emergent effects that occur when these categories intersect" (p. 458). One area of research that uses a both/and approach to social categories is referred to as the multiple jeopardy-advantage hypothesis (Ransford, 1980). Multiple jeopardy (or advantage) is said to occur when individuals possess 
multiple subordinate (or dominant) status social identities. The intersection among one's social identities creates one that is unique and that cannot be explained by each identity component, only by their intersection.

One way that a "both/and approach" can be tested is by using a factorial design. This design can be useful in understanding whether and to what extent master categories or their interactions are meaningful under particular circumstances. Certainly, this design has its limitations, as there are a limited number of identities that can be studied with factorial designs. Nonetheless, it can be an effective strategy for studying social categories, particularly because most of the research using intersectionality theory has used qualitative methods. The studies that have utilized qualitative methods have highlighted how individuals experience, negotiate, and understand their multiple social identities.

\section{Intersectionality and Qualitative Studies of Multiple Social Identities}

Qualitative research has long focused on individuals' multiple social identities with studies spanning the experiences of African American adolescents, Muslim immigrants, female firefighters, and gay and lesbian police officers. In one such study, researchers examined multiple social identities among African-American female adolescents in order to gain an understanding of their sense of identity (or ego identity) from a developmental perspective (Shorter-Gooden \& Washington, 1996). Many of the adolescents cited either racial or gender identity as being central components of their overall identity. However, there were also some who identified the connection between their gender and racial identity, noting that the double oppressions that they experience as black females made their experiences unique from non-black females and black males. 
A similar finding was revealed in the domain of immigrant research (Zaal, Salah, \& Fine, 2007). In this study, Muslim-American young women completed surveys about issues such as identity and discrimination (Zaal et al., 2007). As part of the study, they created identity maps and participated in focus groups, where they discussed similar topics to those raised in the surveys. The young women did not define themselves in singular terms. Rather, they all identified using multiple social identities. Particularly interesting in light of intersectionality is the notion of identity fusion. Specifically, many of the participants noted that the combination of their different identities created a unique culture or perspective. To them, they were neither solely Muslim nor American. One participant described being "like one of those new restaurants that mix...you're like a fusion... a new fusion" (Zaal et al., 2007, p. 168). As reflected in this statement, the fusion of these two social identities represents a unique, hybrid version of identity for these young women (Zaal et al., 2007).

Qualitative research has also examined how female firefighters experienced multiple social identities (Yoder \& Aniakudo, 1997; Yoder \& Berendsen, 2001), noting the importance of exploring how race and gender are inseparable and enmeshed with one another. The experiences of 22 African American female firefighters were compared to those of 24 white female firefighters as obtained through an extensive survey and interview (Yoder \& Berendsen, 2001). They emphasized that, "black women firefighters worked as Black women, not as Black women or Black women, never separating or putting aside these two conceptually distinct aspects of their social identities" (Yoder \& Berendsen, 2001, p. 27, emphasis in original). 
Finally, a recent study examined the experience of gay and lesbian police officers (Miller, Forest, \& Jurik, 2003). This study highlighted the intersecting nature of multiple social identities based on sexual orientation and gender among the officers. A homosexual identity had different connotations for the males and females, emphasizing how the particular combination of identities affects societal meanings, and thus perceptions and experiences. Several lesbian officers noted that their experience was easier than those of gay male officers or heterosexual female officers because others often assumed their homosexuality as female officers. For gay males, the situation was often challenging because of pressure to prove their masculinity in order to gain respect among their fellow heterosexual male officers.

All of these studies have shed light on the understanding of individuals' subjective experience of their multiple social identities (particularly those whose composition included several subordinate identities). However, there are several weaknesses inherent in qualitative research. First of all, all of these studies have had limited samples in terms of their size and composition. None of the studies had more than a couple dozen participants. Also, many of them have used highly specific samples. For example, the sample of African American adolescents was composed only of members from the Black Student Alliance at a particular academic institution (ShorterGooden \& Washington, 1996). Both of these factors limit the generalizability of the findings of this research. It is also pertinent to point out that there were no control groups in any of these research designs, limiting the conclusions that are able to be drawn. In addition, qualitative research using an intersectional approach has focused narrowly on the subjective experience of multiple social identities. Certainly, this research has 
provided rich and useful data about how multiple social identities are experienced, but a quantitative approach can also provide important insights about multiple social identities and categorization processes. While quantitative work has historically been flawed by reductionism, this methodology is not inherently limited. In reality, both methodologies have their limitations and this is why employing both to supplement one another is often the best strategy for investigating social psychological phenomena.

Recently, scholars noted that intersectionality research might benefit by expanding scientific inquiry to include both qualitative and quantitative methods (Bowleg, 2008; McCall, 2005). McCall (2005) claimed, "what is restricting feminist research on intersectionality comes down primarily to methods - not substance, theory, or philosophy" (p. 1795) and urged scholars to see the limits of linking specific methodologies to philosophies of science because it prevents the free flow of knowledge. For this reason, she argued that researchers must diversify their approaches in their examination of intersectionality by using quantitative methods. Bowleg (2008) echoed this sentiment and offered practical advice for conducting intersectionality research. She pointed out that the field of psychology has not done an adequate job in "promoting the understanding of intersectionality" and has tended to view social identities as being unidimensional (Bowleg, 2008, p. 313).

An investigation of perceptions of intersecting social identities has been neglected by intersectionality researchers using qualitative methods. Qualitative research has illuminated how multiple social identities are experienced, but not how they are perceived by others. Past research suggests that others' perceptions can impact individuals' subjective experiences and behaviors. For instance, research on behavioral 
confirmation processes suggests that perceiver expectations affect target behavior. In one study, Caucasian participants who were primed with the stereotype of hostility were more likely to rate their African American interaction partner as being hostile than those not primed. Interestingly, African American interaction partners were also more likely to display hostile behavior than their counterparts who interacted with someone who had not been previously primed, as rated by both the interaction partner and an independent judge (Chen \& Bargh, 1997). This research highlights the symbiotic relationship between subjective experiences and perceptions of intersecting social identities within the framework of intersectionality theory.

It is a mistake to view intersectionality solely as an "alternative" or "feminist" approach. Rather, an intersectionality theory can best be viewed as an overarching theoretical framework for understanding the social psychological and social cognitive research examining how social categories are processed and social identities are experienced by both social perceivers and actors. Intersectionality researchers can learn from social cognitive research in the employment of quantitative methods and research designs. Additionally, social psychological and cognitive research can benefit from intersectionality theory by explicitly recognizing the effects of the social meaning attached to particular social identities due to their position within societal hierarchies of privilege and subordination. Together, utilizing both of these approaches will expand the research on multiple social categorization and social identities, and may ultimately lead to a richer understanding of social categorization processes and social identity. 


\section{CHAPTER 2}

\section{SOCIAL CATEGORIZATION}

Categorization is "the process of understanding what something is by knowing what other things it is equivalent to, and what other things it is different from" (McGarty, 1999, p. 1). Social categorization is concerned with how we understand the similarities and differences among people rather than things. As with categories in general, social categories can be arranged in a hierarchical fashion. For instance, male and female are both subcategories of gender, the superordinate category. For the purposes of this paper, multiple categorization involves the combination of different subcategories across superordinate categories. This might involve, for example, the combination of being female, white, and gay when referring to the superordinate categories of gender, race, and sexual orientation.

Beginning with Allport (1954), the social categorization process has been shown to play an integral part in social perception and behavior. Early in its history, the field of social psychology favored the viewpoint of social perceivers as cognitive misers, with limited cognitive capacity and resources (Fiske \& Taylor, 2008). Indeed, engaging in simple social categorizations is an adaptive way of providing social perceivers with rich information while avoiding the need to sacrifice cognitive energy and resources (Macrae

\& Bodenhausen, 2001; van Knippenberg \& Dijksterhuis, 2000). However, this efficiency does not come without costs. Merely categorizing individuals into social categories has significant consequences, including perceived intragroup similarity, biased causal attributions and memory processes, in-group favoritism, and out-group derogation (Wilder, 1986). Another negative consequence of social categorization is stereotype 
activation and their often (inaccurate) application to target individuals (Hall \& Crisp, 2005). Historically, categorization research assumed that individuals were categorized based solely on one social category. This assumption is problematic because it limited social psychologists' understanding of the cognitive processes that affect person perception.

Pointing out these limitations is not to deny that contextual factors can be powerful determinants of category salience and social judgment (Macrae, Bodenhausen, \& Milne, 1995). The stereotype threat literature, for instance, clearly demonstrates that priming one social category has significant consequences on subsequent task performance (Steele \& Aronson, 1995). In one study, Shih, Pittinsky, \& Ambady (1999) made either race or gender salient to Asian women before completing a math test. They found that when gender was made salient, participants performed worse on the math test compared to when race was made salient. This occurred because math performance is related to negative stereotypes for women, but positive stereotypes for Asians. Nevertheless, it is also important to understand the circumstances in which attending to more than one category or a particular combination of categories provides valuable information and is likely to occur.

\section{Multiple Categorization}

In the 1990s, the view of social perceivers as motivated tacticians came into favor, which specified humans as fully engaged thinkers whose cognitive processes are guided by their goals, motives, and needs (Fiske \& Taylor, 2008). This model is consistent with the notion that, under some circumstances, people can and will activate multiple social categories. With the shift to the motivated tactician model, researchers 
turned their focus toward the investigation of categorizing the self and others on multiple category domains, and gaining an understanding of the factors that influence multiple social categorization (Bodenhausen, 2009; Crisp, Hewstone, \& Rubin, 2001; Sinclair \& Kunda, 1999). One of the major assumptions currently underlying the multiple categorization literature and reflecting the human capacity for cognitive flexibility is that everyone is multiply categorizable (for a recent review, see Crisp \& Hewstone, 2007). While this is an important and necessary step in advancing categorization research to reflect the richness and complexity of social categories, this body of literature remains limited in its scope.

The multiple categorization literature rests upon two key assumptions (Crisp \& Hewstone, 2007). The first is that people can and do engage in multiple categorization for the purposes of social judgment. In one study looking at the use of multiple categories for a memory task, participants read a short paragraph ostensibly taken from a local newspaper and were told that the experimenter was interested in how people read the stories (Crisp \& Hewstone, 2001). After forty-five minutes passed, participants were unexpected asked to recall specific information about the character in the story. They found that participants were able to recall information based on multiple categories (gender and religion), providing evidence for spontaneous attendance to multiple categories. In another study, participants were told to think about themselves either solely as university students or to generate alternative categorizations for themselves (e.g., nationality) (Hall \& Crisp, 2005; Study 1). Participants in the multiple categorization condition demonstrated significantly less intergroup bias compared to the control group in an evaluation task of ingroup and outgroup members. 
The second key assumption of multiple categorization is that the process of categorizing the self and others leads directly to an accentuation of differences between and similarities within social groups. This is the underlying assumption of many identity theories including social identity theory (Tajfel \& Turner; 1979) and self-categorization theory (Turner, Hogg, Oakes, Reicher, \& Wetherell, 1987). According to Crisp \& Hewstone (2007), if strengthening category boundaries accentuates between group differences, then weakening category boundaries should lead to the attenuation of between group differences and an increase in perceived between group similarities. It is based on the idea that multiple categorization leads to decategorization, individuation, and ultimately a reduction in intergroup bias.

The primary type of multiple categorization that has been studied by social cognitive researchers is known as crossed categorization, which involves the simultaneous salience of two category dimensions when making group-level judgments (Brewer, Ho, Lee, \& Miller, 1987; Crisp \& Hewstone, 1999, 2000; Miller, Urban, \& Vanman, 1998). For instance, take the example of making the categories of gender and sexual orientation salient to individuals. Instead of considering only females versus males or homosexuals versus heterosexuals, in crossed categorization contexts perceivers attend to both of these dimensions. The main goal of research focusing on crossed categorization has been to reduce of intergroup bias by explicitly making points of shared identity or categorization salient. Thus in the above example, males and females share a common category when they are both homosexual or both heterosexual. The crosscutting nature of two categories is of primary significance in this area of research. However, category content and meaning, based on the social structural context in which 
these categories are positioned, is largely ignored. In addition, much of this research has examined the benefits of crossed categorization for reducing intergroup using temporary group memberships or memberships like university affiliation or academic major that hold little meaning in the social world.

Other research in this area takes a similar focus regarding stereotype inhibition and activation of salient categories. Sinclair \& Kunda (1999) examined the mediating factors affecting category activation and inhibition in the presence of multiple stereotypes. Across four studies, they found that people activated stereotype congruent and inhibited stereotype incongruent categories when there were multiple stereotypes present. Specifically, in the first study, white participants were given either praise or criticism from a Black manager. When given praise, participants inhibited the Black stereotype and evaluated the manager positively. When criticized, participants activated the Black stereotype resulting in a negative evaluation of the manager. This study did not find evidence that suggests simultaneous activation (or inhibition) of categories. Perhaps this is a function of the fact that this is simply the way that individuals categorize others. However, I would argue that it is more representative of a limitation in the perspective taken by social cognitive researchers, and that there are circumstances when individuals categorize others using more than one social category simultaneously.

The issue of multiple categories is commonly referred to as the "multiple category problem" (Bodenhausen \& Macrae, 1998, p. 10) because the task of studying how several categories are activated and interpreted by perceivers is a daunting one. Kunda \& Thagard (1996) proposed that all of the individuating information about a person will be simultaneously activated and converge to form a summary impression that accommodates 
the different aspects that comprise one's knowledge of the target. This happens through a process of mutual constraint whereby the activated categories affect how the other categories are interpreted. It is not clear what type of process is involved in forming this summary impression, though. Bodenhausen \& Macrae (1998) offer a variation on this perspective. They argue that an additive or multiplicative process is too effortful and that because it is cognitively more efficient people simply activate and amplify one category and treat all others as background noise by actively inhibiting some attributes. Consequently, Bodenhausen \& Macrae (1998) adopt a view in which identities are usually not activated together. However, they do not deny the possibility for simultaneous activation of identities, noting that under conditions of high motivation, perceivers may consider multiple aspects of a target's identity.

Kulik, Roberson, \& Perry (2007) examined the "multiple category problem" in an organizational setting by considering the factors that are most influential in the hiring process when an applicant can be categorized in multiple ways, such as when someone is both black and physically disabled. They propose a matching model where contextual factors are the most important in determining which category will likely be activated, and not the categories themselves. For example, in the context of hiring, the congruency of job requirements with particular stereotypes (even if they are negative) associated with different categories to which a target belongs will be most important in figuring out which category will be made salient. If aggressiveness is an important job requirement, and the interviewer subscribes to traditional stereotypes, then the black category will be activated and the disabled category inhibited. Kulik and her colleagues noted that the two categories will not be combined because it is difficult to integrate them into a single 
coherent assessment of the target. They do not make any assertions about how the process might work when categories are not competing, leaving open the possibility that non-competing categories may be activated together. Despite the challenges associated with conducting multiple categorization research, inroads into the processes underlying at it have recently been made.

\section{Managing Multiple Social Categories}

Multiple category management refers to how specific psychological structures and processes affect the relationship among multiple social identities. Bodenhausen (2010) identified three models of multiple category management. The first model is known as dominance (Roccas \& Brewer, 2002). This pattern is characterized by the primacy of one particular identity in affecting perceptions, evaluations, and behaviors toward an individual. From the perspective of the actor, only one category affects how one defines his or her social identity and associated behaviors and attitudes. A pattern of dominance is reflected in black women's attitudes toward the Million Man March and OJ Simpson trial, for example (Gay \& Tate, 1998). From the perspective of the perceiver, a pattern of dominance occurs when just one social category often affects how a target is reacted to or evaluated.

The second model of multiple category management is known as compartmentalization and occurs when separate, unrelated identities alternate dominating social perception. Often the context of the situation has a great effect on which identity is likely to dominate how a target individual is perceived. Different situational factors will yield differing perceptions of the same individual. For instance, if a black woman finds herself in a room of black and white men, her gender is likely to dominate how she is 
perceived. If that same black woman finds herself in a room full of white women, her race is likely to dominate others' perceptions. Social psychologists have amassed a large body of work by manipulating category salience and subsequently measuring category accessibility (e.g., Macrae, Bodenhausen, \& Milne, 1995; Shih, Pittinsky, \& Ambady, 1999). These types of studies have shown that when one identity is primed and thus made more easily accessible that it will dominate perceptions of target individuals. In the now classic study, participants observed either an Asian woman eating with chopsticks or applying makeup and then performed a lexical decision task where they indicated whether the word was English or not (Macrae et al., 1995). Reaction times indicated that ability to recognize words that are associated with the salient category (either race or gender) was facilitated while the other was inhibited. When the woman was eating with chopsticks and race was salient, people recognized race-related words quicker and when she was applying makeup and gender was salient, they were quicker at recognizing gender-related words as English. Returning to the example above, what happens when that same black woman is in a room full of white men? Which identity will dominate how she is perceived? This leads to the third model of multiple category management that Bodenhausen identified called integration.

Integration occurs when an individual's multiple social categories are simultaneously observed and combined in some manner to form impressions. Subtyping and subgrouping are instances of an integration model of multiple category management (Crisp \& Hewstone, 2007). While these two processes are closely related, they are distinct. Subtyping occurs when "disconfirming members of the superordinate group are psychologically 'split off' from the group as a whole” (Crisp \& Hewstone, 2007, p. 215). 
Subgrouping, on the other hand, occurs when members of a superordinate group are divided into smaller, more meaningful groups.

Crisp \& Hewstone (2007) outline five different patterns of integration for social judgment that are dependent on ingroup and outgroup status of the target individual. The first is additive and occurs when category salience is equivalent. Evaluations are simply made in an additive fashion. This pattern is based on the assumption that ingroups are evaluated more positively than outgroups. Thus, when a perceiver and target share multiple ingroups, evaluations will be most positive. On the other hand, when a perceiver and target have multiple outgroups, evaluations will be most negative. For those targets who have mixed ingroup and outgroup statuses with the perceiver, evaluations will be somewhere in between these extremes. Next, is the social inclusion pattern which posits that all groups will be evaluated equally positively as long as there is a common ingroup on at least one category dimension. The social exclusion pattern is the opposite of social inclusion. Thus, mixed targets are evaluated as negatively as double outgroups because they are an outgroup on at least one dimension. Hierarchical rejection is the next pattern and specifies that outgroup membership on the more important dimension will determine evaluation (e.g., male supporters only derogating the female players on an opposing softball team). In this example, gender is the more important dimension and team membership is the less important second dimension. The last pattern is called equivalence and occurs when there are no differences in evaluation across the subgroups. All of these patterns are based solely on ingroup and outgroup status of the social perceivers and targets, but do not recognize how status differences among these categories might affect patterns of perception. 
While recent social cognitive research on multiple social categorization has been fruitful, its focus has been limited to investigating the consequences of multiple categorization on intergroup relations. Social cognitive researchers have paid little attention to variables aside from ingroup and outgroup status that might also affect how multiple social categories might be perceived. Recently, research using an intersectionality approach to examine social identities with quantitative methods has been conducted. This growing body of research may inform how social cognitive approaches to studying the effects of multiple social categorization.

\section{Examples of Quantitative Research Using an Intersectionality Approach}

Steinbugler and her colleagues attempted to operationalize intersectionality in order to examine the effects of gender and race on attitudes toward affirmative action (Steinbugler, et al., 2006). Participants were randomly assigned to evaluate hiring practices and job training based on race and gender resulting in three conditions: black people in general, black women, and black men. They found that the intersection between race and gender had an effect on whites' attitudes toward affirmative action. Specifically, whites showed the most opposition to affirmative action when black women were the targets compared to black people in general and black men. White people showed the least amount of opposition to affirmative action toward black men. The implication of this finding is that specific combinations of race and gender affect attitudes toward, in this case, affirmative action. These findings suggest that the examination of the interactive effects of race and gender is critical to understanding of perceptions of individuals. 
Purdie-Vaughns and Eibach (2008) recently introduced a model of how individuals' multiple social identities are perceived, known as intersectional invisibility. This is an exceptional example of how intersectionality can affect the way that social psychologists approach the study of multiple categorization. Intersectional invisibility can best be thought of as a specific type of intersectionality, positing that individuals who are not prototypical group members (e.g., lesbians in gay communities and black women in black communities) often go unseen because of their intersecting subordinate-group identities. The implications of such erasure have far-reaching consequences in political, cultural, and legal domains. A pair of studies that examined how targets that varied by race (black and white) and gender (male and female) were perceived by mostly white participants provided empirical support for this model (Goff, Thomas, \& Jackson, 2008). They found that black women were rated as being more masculine than white women and as being least attractive compared to white women and black and white men. An underlying assumption of this research is that a woman is defined by her femininity and to the extent that she is perceived as feminine, she is rated as being more attractive. While black women are not literally unseen, ratings of them on these defining variables of womanhood demonstrate that they are figuratively rendered invisible as women. In addition, they found that when categorizing the target by race and gender, participants made the most errors with black women. Another way of putting this is to say that black women are often not accurately categorized as black women. Instead, they are most often miscategorized (relative to other intersecting categories) as men or as white. Because black women do not fit the prototype of black people (i.e., men) or women (i.e., white), they are unacknowledged and unseen. An approach to person perception using 
intersectional invisibility differs from the social cognitive research outlined above in its focus on how the process of multiple categorization affects perceptions of target individuals who inhabit particular social categories or identities (i.e., those associated with subordinated statuses) instead of merely focusing on the combination itself. Intersectional invisibility makes predictions for category processing based on a specific property (i.e., prototypicality) of each category that comprises the category conjunction.

My research expands upon both the social cognitive research and intersectionality research through its explicit acknowledgement of social meaning and status attached to particular social categories and by using quantitative methods to approach the study of multiple social identities/categorization. In the present studies, I seek to take an intersectional approach using quantitative methods to examine perceptions of individuals' multiple social identities based as race, gender, and sexual orientation. In Study 1, I used measures of overall impression and personality traits to investigate how the perception of combining social identities is affected. The primary goal of Study 1 was to show that person perception is dependent upon the combination of multiple social identities. The purpose of Study 2 was to examine the cognitive processes underlying multiple category (or identity) activation based on race and gender. Specifically, the main goal of this study was to demonstrate that multiple category activation can occur under circumstances likely to facilitate it. 


\section{CHAPTER 3}

\section{STUDY 1: INTERSECTIONALITY AND PERSON PERCEPTION}

One of intersectionality's basic tenets is that individuals' multiple social identities must be considered in conjunction with one another to best understand both subjective experience and the perception of individuals. However, few studies in the extant literature using intersectionality as its theoretical framework have examined how individuals' multiple social identities are perceived. I employed an impression formation paradigm to study how different combinations of social identities affect overall impression and personality trait ratings. The current study can be informed by past impression formation research examining the role of different personality traits in the perception and evaluation of target individuals.

\section{Context Effects and Impression Formation}

Early research found support for context effects of negatively and positively valenced traits in person perception (Anderson, 1966, 1971; Anderson \& Lampel, 1965; Asch, 1946; Hamilton \& Zanna, 1974; Kaplan, 1971; Wyer \& Watson, 1969). The inclusion of a global positive word (e.g., good) in a list of traits caused the target individuals to be rated more positively than when a global negative word (e.g., bad) was included in the same list of traits. While this is a robust finding, the interpretation of these effects has been debated. One prevailing model that has been posited to explain these effects is the meaning change theory (Asch, 1946). Asch's meaning change theory hypothesizes that a change in how a trait is evaluated results from a change in how the trait is interpreted in the context of other traits. That is, the meaning of one trait is dependent upon the other traits in the list. For instance, in one study, participants were 
given the following list of descriptors - intelligent, skillful, industrious, determined, practical, and cautious and then asked to report their impressions of the individual. The list differed in only one respect, the inclusion of the characteristic warm or cold. Rather than causing an incremental change (in a positive or negative direction) in impressions, Asch (1946) found that overall impressions were affected. The inclusion of each of those characteristics was related to an overall shift in how people characterized the individual resulting in major evaluative discrepancies.

The results from Asch's studies can also be used to understand the relationship among an individual's various social identities. Like personality traits, social identities are also dependent on one another for meaning according to an intersectionality theory. Building upon Asch's meaning change theory, individuals' social identities can be thought of as the context for their other social identities. For example, the identity of woman (as opposed to man) might change one's overall impression of an individual whose other identities include Asian American and heterosexual. Thus, overall impressions are affected by the combination of an individual's multiple social identities because each social identity a person has differentially affects how the others are perceived. In the present study, I seek to demonstrate this effect by examining how ratings of overall impression and of personality domains are affected by individuals' multiple social identities based on varying the combinations of race, gender, and sexual orientation.

\section{Behavioral Economics Research and Intersectionality}

Research in the area of behavioral economics can also be used as evidence to demonstrate how multiple social identities can influence how others are perceived and 
approached. While this study (Ayres \& Siegelman, 2001) was not directly concerned with the examination of multiple social identities, it demonstrates how different combinations of social identities differentially influence person perception and ultimately affect behaviors. Ayres \& Siegelman (2001) investigated discrimination of individuals during negotiations for the purchase of a car and found that compared to black men and women and white women, white men were offered the lowest price for the car. White women were charged approximately $\$ 200$ more than white men. Black men were the most discriminated against and were, on average, charged more than $\$ 900$ more than white men. Intersectionality posits that multiple social identities have to be considered together and that they are often more complex than simply adding together the effects of each individual identity - in this case, race and gender. If an additive approach was taken, then it would logically follow that black women would be charged $\$ 1100$ more than white men. However, black women were only charged $\$ 400$ more than white men. This study highlights the consequences of intersectional invisibility (Purdie-Vaughs \& Eibach, 2008), providing further evidence for an approach to multiple social identities that is informed by intersectionality.

\section{Dual Process Models of Impression Formation}

Two models of impression formation that have dominated social psychology are Brewer's (1988) dual process theory and Fiske and Neuberg's (1990) continuum model. Both theories suggest that impression formation is comprised of two processes: categorization and individuation. Brewer (1988) posited that when we form impressions of others we either use a top-down heuristic, focusing on categorizing the target or a bottom-up systematic approach, which focuses on individuating. Similarly, the 
continuum model (Fiske \& Neuberg, 1990) theorized that impressions are made on a continuum that covers the span between category-based processing at one end to attribute-based processing at the other. Fiske and Neuberg argued that people do not individuate or categorize others. Rather, level of processing to form impressions can best be thought of on a continuum, being more or less categorical or more or less individuating, but not strictly one or the other. Where these theories of impression formation converge is on their focus on singular categorization. According to these theories of impression formation, multiple categorization is not an option for impression formation. Thus, multiple categorization is synonymous with decategorization or individuation, which has the effect of erasing the social meaning attached to multiple social identity combinations. An intersectionality approach does not follow either a categorization or individuation process, as posited by Brewer (1988) or Fiske and Neuberg (1990). Instead, an intersectionality approach to social identity hypothesizes that an individual can and will be categorized based on multiple social categories. According to intersectionality theory, it is not a choice between either categorization or individuation. Rather, understanding social identity is about simultaneously recognizing the meaning attached to particular identities, as well as the commonalities that we all share as human beings (Cole, 2008).

Rationale for the Current Research

While past research can inform us about how individuals' multiple social identities affect overall impressions (Asch, 1946) and behaviors such as discrimination (Ayres \& Siegelman, 2001), there continues to be a dearth of research whose primary goal it is to examine the effects of individuals' multiple social identities on perception 
using quantitative methods (for exceptions, see Goff, et al., 2008; Steinbugler, 2006). Until recently, the majority of intersectionality research was conducted using qualitative methodology (Miller et al., 2003; Shorter-Gooden \& Washington, 1996; Yoder \& Berendsen, 2001; Yoder \& Aniakudo, 1997; Zaal et al., 2007). Therefore, the primary goal of Study 1 was to examine multiple social identities, using quantitative methodology. In addition, I sought to extend the literature by examining perceptions of individuals' multiple social identities. My primary hypothesis was that person perception would be affected by how different social identities (with different social meanings) were combined within an individual. In order to test this, I employed an impression formation paradigm to examine others' perceptions of individuals' multiple social identities.

Participants were given an ostensible roommate survey through which they learned the target individual's race, gender, and sexual orientation. Subsequently, they rated their overall impression of the target, in a fashion similar to that used by Asch (1946). Using impression ratings as a dependent variable allowed me to assess the nature of the change (e.g., incremental or qualitative), based on the social identities of the target. Past research has found that people are able to make reliable personality ratings based on very little information about an individual like the style of one's handshake, items in one's office or bedroom, and simply seeing the person walk across a room (Borkenau, \& Liebler, 1992; Chaplin, Phillips, Brown, Clanton, \& Stein, 2000; Gosling, Ko, Mannarelli, \& Morris, 2002). Therefore, participants also assessed the target on six personality dimensions including honesty-humility, emotionality, extraversion, agreeableness, conscientiousness, and openness to experience. Traditional social psychological approaches to multiple social identities would predict main effects for each 
of these factors (i.e., race, gender, and sexual orientation). However, the major prediction of this study was that perceptions of others' various social identities would result in significant interactions among them.

\section{Method}

\section{Participants}

Four hundred and forty five people (284 females; 153 males; 8 not identified) participated in the study. Participants' ages ranged from 17-years-old to 45-years-old, ( $M$ $=20.19 ; S D=2.88)$. Most participants self-identified as Caucasian $(55.1 \%)$. The remainder of the sample self-identified as African American (22\%), Asian American (9.4\%), and Hispanic American (3.6\%). About 9\% of the sample identified as "Other", and $.4 \%$ chose not to identify their race. One participant did not complete all of the measures; therefore all further analyses are based on a sample of 444 participants (unless otherwise stated).

Procedure

Participants were recruited at Temple University, a large urban university, via an online participant sign-up system to participate in a study about perceptions of potential roommates. Participants completed the study in groups of up to 8 individuals at a time. After completing the informed consent process, participants were told to read the Housing and Residence Life Roommate Survey that was ostensibly completed by another undergraduate student. Subsequently, participants evaluated their overall impression of the target individual and completed the 100-item HEXACO personality inventory about the target individual. Because past research suggests that having an accuracy goal in impression formation leads to the use of complex cognitive processes (Neuberg \& Fiske, 
1987), participants were told to, "be as accurate as possible based on all the information" they had about the target individual.

\section{Materials}

Housing and Residence Life Roommate Survey. The Housing and Residence Life Roommate Survey included information about the target individual's sleep and wake time, optimal studying conditions and habits, and cleaning habits (See Appendix A). These variables (i.e., those related to study and living habits) remained constant across condition. The experiment employed a 2 (target gender: female or male) X 2 (target race: African American or Caucasian) X 2 (target sexual orientation: gay/lesbian or heterosexual) between subjects factorial design. Participants were randomly assigned to one of eight conditions which included: Caucasian heterosexual male $(n=51)$, Caucasian heterosexual female $(n=54)$, Caucasian gay male $(n=56)$, Caucasian gay female $(n=$ 55), African American heterosexual male $(n=56)$, African American heterosexual female $(n=53)$, African American gay male $(n=56)$, and African American gay female $(n=63)$. Uneven cell sizes are the result of research assistant administrative errors.

Target Ratings of Overall Impression. Participants rated their overall impressions of the target individual on three items. Specific items included: overall, I have a favorable impression of him/her, if I were to meet this person, I would like him/her, and I would be friends with this person. Responses were made on a five-point rating scale ranging from 1 (strongly disagree) to 5 (strongly agree). Together, these three items yielded high internal consistency $(\alpha=.81)$ and were combined into a composite target impression rating. 
HEXACO-Personality Inventory Revised. The HEXACO-PI-R has demonstrated high levels of internal consistency reliabilities and demonstrated acceptable levels of convergent validity with other personality (Lee \& Ashton, 2004; Lee \& Ashton, 2006; Lee, Ashton, Pozzebon, Viser, Bourdage, \& Ogunfowora, 2009). Participants rated the target individual on a five-point rating scale ranging from 1 (strongly disagree) to 5 (strongly agree). Ratings were made along six personality dimensions: honesty-humility $(\alpha=.58)$, emotionality $(\alpha=.71)$, extraversion $(\alpha=.81)$, agreeableness $(\alpha=.82)$, conscientiousness $(\alpha=.83)$, and openness to experience $(\alpha=.73)$. Each dimension was comprised of 16 individual items that are divided into four sub-dimensions (for exact items and sub-dimensions, see Appendix B). The role of the sub-dimensions is to provide facets that comprise each dimension. Only 4 items are included in each facet and often yield low levels of internal consistency. Therefore, it is recommended that they are only to be used as predictors of conceptually related criterion variables or as indicators of the HEXACO dimensions. HEXACO personality dimensions were scored based on scoring procedures outlined by Lee et al. (2009). After reverse coding the necessary items (See Appendix B for specific items), factor scale scores were computed as the means across all items in the factor. Items were presented in a fixed random order.

\section{Results}

The primary goal of Study 1 was to investigate whether different combinations of multiple social identities based on race, gender, and sexual orientation differentially affect the evaluation of a target individual. Traditional social psychological theorization would predict main effects for each factor (i.e., target gender, target race, and target sexual orientation) and no interactions among them. An intersectional approach to 
perceptions of target individuals is supported if there are significant two-way or threeway interactions among the independent variables.

Target Ratings of Overall Impression. The primary hypothesis was that I would observe interactive effects for overall impression of the target individual. Thus, an analysis of variance (ANOVA) was performed in order to examine the amount of variance accounted for by the main effects alone and the additional influence of interaction terms. Therefore, I performed a step-wise analysis with the three main effects (i.e., target race, target gender, and target sexual orientation) entered in the first step. In the second step, all possible two-way interactions (i.e., target race $\mathrm{X}$ target gender, target race $\mathrm{X}$ target sexual orientation, and target gender $\mathrm{X}$ target sexual orientation) and the three-way interaction term (i.e., target race $\mathrm{X}$ target gender $\mathrm{X}$ target sexual orientation) were entered. For overall impression ratings, I found that the interaction terms accounted for a significant amount of the variance above and beyond the main effects alone, $R_{\text {change }}^{2}$ $=.02, F(4,437)=2.64, p=.03$ (See Table 1). Follow-up tests examining all possible 2way and the 3-way interaction revealed a significant 2-way interaction between race and sexual orientation, $F(1,437)=5.96, p=.02, \omega^{2}=.01$. All other 2-way interactions were not statistically significant both $F \mathrm{~s}<1, n s$. In addition, there was a significant 3-way interaction between target race, target gender, and target sexual orientation, $F(1,437)=$ $4.16, p=.04, \omega^{2}=.007$. These findings provide support for an intersectionality approach to forming impressions of others' various social identities.

Target Ratings of Personality Dimensions. I was also interested in examining how different combinations of identities might differentially affect personality ratings. An identical analysis of variance (ANOVA) as described above was performed in order to 
examine the amount of variance accounted for by the main effects and interaction terms for each of the six personality dimensions (See Table 1). Because I did not have a specific hypothesis for the six personality dimensions, I performed a Bonferroni correction to control the Type I error rate across the six tests. I found that the interaction terms accounted for a significant amount of the variance above and beyond the main effects alone for emotionality $R_{\text {change }}^{2}=.04, F(4,436)=4.80, p<.05$. Analyses yielded non-significant results for honesty, extraversion, agreeableness, conscientiousness, and openness, all $F_{\mathrm{s}}<2.64, n s$. Follow-up tests examining all possible 2-way and the 3-way interaction for emotionality revealed a significant 2-way interaction between target gender and target sexual orientation, $F(1,436)=16.42, p<.001, \omega^{2}=.03$. All other interactions were not statistically significant, all $F$ s $<2.15, n s$.

Pairwise Comparisons of Overall Impression and Personality Trait Ratings by Condition. I also performed post-hoc analyses to examine exactly how the specific combinations of social identities affected ratings of overall impression and the six personality dimensions. I performed pairwise comparison tests to compare all possible combinations of the conditions for each dependent variable (see Table 2). In order to control for Type I errors, a Tukey's HSD test was computed.

For overall impression, African American heterosexual males were rated more favorably $(M=4.08, S D=.70)$ than African American gay males $(M=3.67, S D=.58 ; d$ $=.64)$ and African American gay females $(M=3.71, S D=.70 ; d=.53)$. All other target individuals were rated the same on overall impression.

I found no differences between the eight conditions for the personality dimensions of extraversion, agreeableness, or conscientiousness. All of the targets were rated the 
same regardless of the specific combination of their social identities for those three personality traits. For honesty, only Caucasian gay females $(M=3.28, S D=.33)$ and African American gay males $(M=3.07, S D=.32)$ were significantly different from one another with Caucasian gay females being rated as more honest than African American gay males $(d=.65)$. I found no differences between honesty ratings for the other conditions. For emotionality, Caucasian heterosexual males $(M=2.67, S D=.36)$ and African American heterosexual males $(M=2.70, S D=.36)$ did not differ. All other conditions were significantly different from Caucasian and African American heterosexual males, but not from one another. This set, which included Caucasian heterosexual females, Caucasian gay males and females, African American heterosexual females, and African American gay males and females, was perceived as significantly more emotional than Caucasian or African American heterosexual males (smallest $M=$ 2.91, $S D=.26$ ). Effect sizes for the pairwise comparisons with Caucasian heterosexual males ranged from $d=.71$ (Caucasian gay females) to $d=.98$ (African American gay males). For African American heterosexual males, effect sizes for the pairwise comparisons ranged from $d=.63$ (Caucasian gay females) to $d=.91$ (African American gay males). On openness, Caucasian heterosexual males $(M=3.00, S D=.42)$ were perceived as significantly less open than Caucasian gay males $(M=3.21, S D=.26 ; d=$ $.61)$ and females $(M=3.31, S D=.32 ; d=.83)$ and African American gay females $(M=$ $3.23, S D=.37 ; d=.59)$. Caucasian gay males $(M=3.21, S D=.26)$ were rated as significantly more open than Caucasian heterosexual females $(M=3.01, S D=.31 ; d=$ $.70)$ and African American heterosexual males $(M=2.96, S D=.34 ; d=.83)$. In addition, African American gay females $(M=3.23, S D=.37)$ were rated as significantly more 
open than Caucasian heterosexual females $(M=3.01, S D=.31 ; d=.64)$ and African American heterosexual males $(M=2.96, S D=.34 ; d=.76)$.

\section{Role of Participant Race and Participant Gender on Target Ratings. I also}

conducted an exploratory analysis to examine the role of participant race and participant gender on personality and overall impression ratings of the target individual. For race, I restricted the analysis to include only African American $(n=97)$ and Caucasian $(n=244)$ participants because the sample sizes for other participant races were not sufficient to conduct similar analyses (See Table 3 for means and SDs). A two factor ANOVA was conducted for each dependent variable. There was no significant main effect for participant race (all $F \mathrm{~s} \leq 1$ ) for any of the dependent variables. All interactions between participant race and target race were also not significant (all $F \mathrm{~s} \leq 2$ ).

Finally, I examined the role of participant gender on target ratings of personality and overall impression. This analysis included 152 males and 282 females (See Table 4 for means and $S D$ s). Again, a two factor ANOVA was conducted for each dependent variable. I found a significant main effect of participant gender for overall impression, $F(1,437)=7.14, p=.01, \omega^{2}=.01$, honesty, $F(1,436)=5.87, p=.02, \omega^{2}=.01$, extraversion, $F(1,436)=4.18, p=.04, \omega^{2}=.01$, and agreeableness $F(1,436)=4.96, p=$ $.03, \omega^{2}=.01$. For overall impression, female participants $(M=3.89, S D=.61)$ perceived all target individuals more favorably than did male participants $(M=3.72, S D=.66)$. For honesty, female participants $(M=3.20, S D=.29)$ perceived all target individuals as being more honest than did male participants $(M=3.12, S D=.34)$. For extraversion, female participants $(M=3.65, S D=.40)$ perceived the target individuals as being more extraverted than did male participants $(M=3.57, S D=.39)$. For agreeableness, female 
participants $(M=3.32, S D=.44)$ perceived the target individuals as being more agreeable than did male participants $(M=3.23, S D=.45)$. No significant main effects of participant gender were found for emotionality, conscientiousness, or openness (all $F \mathrm{~s} \leq$ 2.72). I found a significant interaction between target gender and participant gender for openness, $F(1,431)=4.14, p=.04, \omega^{2}=.01$ (See Figure 1). Simple effects analyses revealed that male participants differentially rated female targets and male targets, $F(1,432)=9.48, p=.002$. As shown in Figure 1, male participants rated female targets $(M=3.14, S D=.35)$ as significantly more open relative to male targets $(M=3.03, S D=$ .42). Female participants did not rate male $(M=3.12, S D=.30)$ and female targets $(M=$ $3.14, S D=.35)$ differently on openness, $F(1,432)=.58$, ns. No significant interactions were found for the other dependent variables (all $F \mathrm{~s}<1$ ).

\section{Discussion}

The main goal of study 1 was to investigate whether the perception of intersecting social identities affected target evaluations more than singular social identities. For overall impression, I found a significant interaction among race, gender, and sexual orientation. Thus, overall impression ratings were dependent on the combination of social identities, not any one particular identity type. One of the biggest differences in overall impression ratings was between African American heterosexual males and African American gay males. African American heterosexual men were rated the most favorably while African American gay males were rated least favorably. Providing strong evidence of the utility of an intersectional approach to person perception is the finding that the interactions among race, gender, and sexual orientation accounted for 
more than twice as much of the variance in overall impression ratings than the main effects alone.

Traditional social psychological theories on identity predict that the addition of each identity type would affect ratings in an identical fashion independent of one's other identities. However, I found evidence congruent with Asch's (1946) meaning change hypothesis and indicative of an intersectional approach to social identities. While I found only a significant three-way interaction for overall impression and not for any of the personality dimensions, the presence of significant main effects of race, gender, and sexual orientation does not necessarily provide evidence counter to intersectionality. As Cole (2009) points out, an intersectional approach to social identities allows for the possibility of an interactive relationship among them, but does not necessarily hypothesize that the relationship among social identities is never additive. In some cases, one type of social identity dominated how the target individual was perceived and evaluated. This finding is consistent with Gay \& Tate's (1998) finding that black women's race dominated their attitudes toward particular cultural events.

In addition, I examined how different combinations of social identities affect person perception using an intersectionality approach. I found evidence that people differentially rated overall impression and the personality dimensions, emotionality, and openness and honesty of the target individual depending on the target's composition of multiple social identities. However, I also found that targets were not rated differently from one another for the personality dimensions extraversion, agreeableness, and conscientiousness. 
In looking at the specific differences in how the different combinations of social identities were rated, I found evidence for reliance on stereotypes in rating the target individual. While not immediately apparent, this finding provides further evidence of an intersectional approach to multiple social identities, as it is not the case that the effects of separate identities can simply be added together to understand how individuals' multiple social identities are perceived. These findings are consistent with a dominance relationship among multiple social categories (Bodenhausen, 2010). When targets had associated specific identity (combination) that was strongly associated with particular stereotypes, I found that it dominated how target individuals were rated. For instance, I found that African American and Caucasian heterosexual males were both rated as less emotional than any other identity combination. Thus, the intersection of male and heterosexual identities dominated how these target individuals were perceived, but race did not have a significant effect. As shown in Appendix B, the emotionality dimension is divided into four sub-dimensions: fearfulness (e.g., When it comes to physical danger, this person is very fearful), anxiety (e.g., This person gets very anxious when waiting to hear about an important decision), dependence (e.g., This person can handle difficult situations without needing emotional support from anyone else, reverse coded), and sentimentality (e.g., This person feels like crying when he sees other people crying). There are extremely powerful stereotypes that dictate what it means to be a man, with some of the most stringent mandates being that a heterosexual male be independent and fearless, and not to openly show emotion like crying, (Eagly \& Mlandic, 1989; Goodey, 1997). In addition, this dimension is congruent with stereotypes of gay men and women as being emotional and in general, feminine (Davies, 2004; Eagly \& Mlandic, 1989). 
A similar analysis can be applied to the openness personality dimension. I found an overall trend for gay targets to be rated as more open regardless of race or gender. The openness dimension was subdivided into four sub-dimensions: aesthetic appreciation (e.g., If this person had the opportunity, he/she would like to attend a classical music concert), inquisitiveness (e.g., This person enjoys looking at maps of different places), creativity (e.g., This person would enjoy creating a work of art, such as a novel, a song, or a painting), and unconventionality (e.g., This person likes people who have unconventional views). Again, stereotypes of gay men and lesbians (Kite \& Deaux, 1987; Madon, 1997; Page \& Yee, 1985) are strongly associated with these characteristics - particularly aesthetic appreciation and unconventionality.

Finally, I found that Caucasian gay females were rated as more honest than African American gay males. All of the other target individuals were rated as equally honest to one another. The similarity in honesty ratings of the other six target individuals should be noted. Intersectionality theory urges scholars "to recognize social categories as specific, historically based, contextualized, intersecting and constructed through power while simultaneously remembering that our common heritage is that we share the experience of life within this web of intersections" (Cole, 2008, p. 451). Thus, it is important that psychologists are not concerned only with finding differences among individuals, but also with highlighting their commonalities. Notably, individuals with different intersections of social identities were perceived similarly on personality ratings of extraversion, agreeableness, and conscientiousness. In the United States, society often overlooks shared experience and perceptions among people who appear to differ from one another on the surface. 
Intersections of social identities not only occur within individuals, but also between individuals. Surprisingly, I did not find any effects of participant race on overall impression or personality dimension ratings. Regardless of whether the participant identified as African American or Caucasian, all of the target individuals were rated similarly on all of the dependent variables. This finding emphasizes the similarity between African American and Caucasian individuals in how they perceive other individuals based on race. Other alternatives should also be considered. Perhaps the racial diversity of Temple University's campus played a role in Caucasian participants' favorable impression ratings of the African American target individuals, as white students may have roommates, close friends, and/or classmates who are African American. Recent research found that for white students, having an interracial roommate was associated with less anxiety in interracial interactions and more positive racial attitudes than having same-race roommates (Shook \& Fazio, 2008). It is also possible that participants provided socially desirable responses. African American target individuals were rated more favorably than Caucasian target individuals despite the prevalence of negative stereotypes of African Americans. Past research has found that individuals who think of themselves as being egalitarian may experience anxiety about being perceived as racist and therefore may overcompensate on explicit measures to ensure that they will not (McConahay, 1986).

Participant gender affected how target individuals were perceived. Female participants had significantly more favorable impressions of the target individuals relative to male participants. In addition, female participants perceived the target individuals as being more honest, extraverted, and agreeable compared to male participants. In the 
United States, females tend to be socialized to be pleasant and happy (McHale, Crouter, \& Whiteman, 2003), which affects not only their own behavior but also their perceptions of others. Social identity theory (Tajfel \& Turner, 1979) suggests that female participants evaluated female targets positively because of their shared ingroup status. To the extent that females positively identify with females at the group level, they will be more likely to evaluate female targets more positively than outgroup members (i.e., male targets).

For the personality dimension of openness, I found a significant interaction between participant gender and target gender such that male participants perceived female target individuals as being more open than they did male target individuals. Female participants did not perceive male and female target individuals differently on the openness personality dimension. This finding may be due to males' stricter adherence to prescriptions of masculinity, as many of the items on this scale relate to a having a penchant for learning, artistic and creative ability, and appreciation of the arts, all of which run counter to hegemonic notions of masculinity (Goodey, 1997). However, I am cautious about making any strong claims about the role of participant race and gender on target perceptions, given that I did not measure any characteristics of participants. At this point, the only claims that I am able to make are based on (inaccurate) assumptions about the categories to which participants belong. Using these categories as explanatory constructs may artificially exacerbate within-group homogeneity and between-group heterogeneity (Helms, Jernigan, \& Mascher, 2005).

Stereotype content may also have played a role in perceptions of the six personality dimensions: honesty, emotionality, extraversion, agreeableness, conscientiousness, and openness. Using overall impression and personality trait ratings 
as dependent variables provided a conservative test of intersectionality compared to studies whose tests rely on stereotypes of particular social identities. The likelihood of finding interactive effects would increase to the extent that traits associated with particular stereotypes were used. In the current study, the strongest stereotypes of African Americans are generally unrelated to the specific items included in the HEXACO personality inventory (e.g., hostile, angry, athletic, musical, etc.; Devine, 1989; Dovidio et al., 1986; Jackson, Lewandowski, Ingram, \& Hodge, 1997).

\section{Study Limitations}

Everyone has innumerable social identities that affect how others perceive them. For the purposes of this study, I chose only three: race, gender, and sexual orientation. I chose race and gender because their effects on intergroup relations have been widely studied within social psychology (Dovidio \& Gaertner, 1993; Stewart \& McDermott, 2004). Additionally, both race and gender are perceived very quickly (Stangor, Lynch, Duan, \& Glass, 1992). Sexual orientation is an increasingly important identity that is the focus of public policy decisions such as service in the military and the right to marry, making it relevant to many Americans. And like race and gender, strong and specific stereotypes are associated with one's sexuality (Davies, 2004; Kite \& Whitely, 1996). While the choice of these particular identities was deliberate and justifiable, it should not detract from the study's scope and ability to examine other important social identities related to physical ability, religion, and socioeconomic status. Additionally, it must be noted that within the identities that I chose to examine there are many other possible identities (e.g., for race, Asian, Hispanic, etc.). Again, examination of more social 
identities was limited due to methodological and statistical constraints associated with conducting psychological research of this nature.

Participants received a very limited amount of information about the target individual. They did not interact with anyone or even see a picture of the target individual. Also, participants' ratings were not outcome dependent (i.e., participants did not believe they would have to interact with the target person). Nonetheless, this type of rating task is a common practice in social cognitive research, and past research suggests that people are able to project a lot about a person based on little information (Borkenau, \& Liebler, 1992; Chaplin, Phillips, Brown, Clanton, \& Stein, 2000; Gosling, Ko, Mannarelli, \& Morris, 2002). In addition, past research has found that having a goal of accuracy (as employed in the current study), is a powerful motivator in impression formation (Neuberg \& Fiske, 1987).

\section{Conclusions}

Study 1 yielded support for an intersectionality approach, demonstrating that the perception of intersecting social identities affected target evaluations of overall impression more than singular social identities. In addition, Study 1 found evidence suggesting that the combination of social identities differentially affected how individuals' overall impression and personality traits of emotionality, and openness were rated. The similarities in target ratings for the personality dimensions of honesty, extraversion, agreeableness, and conscientiousness were also remarkable, given that the target individuals' differing identity intersections. As Cole (2009) noted, an intersectionality approach to social identity allows for different types of relationships between separate identities including one in which one type of identity drives subjective 
experiences and perceptions of others. Certainly, social cognitive researchers have extensively examined when and under what circumstances separate identities are made salient (e.g., Shih, et al., 1999). Much of this research has been limited by its inattention to salience and accessibility of multiple social categories (e.g., Bargh, Bond, Lombardi, \& Tota, 1986; Carver, Gannellen, Froming, \& Chambers, 1983; Erdley \& D’Agostino, 1988; Fazio, Powell, \& Herr, 1983; Herr, Sherman, \& Fazio, 1983; Higgins, Rholes, \& Jones, 1977; Martin, 1986; Skowronski, Carlston, \& Isham, 1993; Williams, 1993; Wyer $\&$ Hartwick, 1980). In general, a singular social category is thought to be activated separately based upon its salience and accessibility (e.g., Gilbert \& Hixon, 1991; Macrae, et al., 1995; Shih et al., 1999).

Traditionally, empirical research supported singular categorization processes that influence the perception of others, in domains including group perceptions (Wilder, 1978a, 1978b), within-group assimilation and between-group contrast (Allen \& Wilder, 1979), outgroup homogeneity effect (Ostrom \& Sedikides, 1992; Park \& Rothbart, 1982; Quattrone \& Jones, 1980), and ingroup bias (Brewer, 1979; Tajfel, Billig, Bundy, \& Flament, 1971). Indeed, social categorization has also been shown to have effects on how information about group members is processed in terms of automatic evaluative reactions (Dovidio \& Gaertner, 1993), causal attributions (Hewstone, 1990; Pettigrew, 1979), and discriminatory behaviors (Diehl, 1990; Tajfel et al., 1971) among others. While social categorization results in information loss for specific individuals, it is also associated with information gain at the group-level (Mackie et al., 1996). This information loss and gain, however, may be inaccurate or misleading given that all of this research has only examined categorization based on only one social category. Traditional 
social psychological theorization and empiricism have been based on an either/or approach to categorization, pitting categories against one another. This approach does not allow for the activation of multiple categories or for the activation of a new, unique category.

Recent social cognitive research found evidence suggesting that simultaneous activation of multiple social categories is possible and can occur spontaneously when given the opportunity (Freeman, Ambady, Rule, \& Johnson, 2008). In a study that specifically investigated the activation of multiple social categories using the mouse trajectory task, Freeman et al. (2008) found evidence suggesting simultaneous activation of two social categories. Using a mouse trajectory paradigm, Freeman and colleagues sought to show that more than one social category could be simultaneously and partially active. Participants were presented with social targets that were able to be categorized in multiple ways based upon gender, race, or age, such as a black male and then told to categorize it based only on one of them (e.g., gender). The correct category was always directly horizontal from the target (in this case, male). Along the vertical axis was an obviously wrong category (e.g., female) and on the other end was a distracter category that was either relevant (e.g., black) or irrelevant (e.g., white) to the social target. They found that when the distracter category was relevant there was significantly more deviation in that direction from an ideal horizontal line. While this study is important because it allows for spontaneous simultaneous activation of multiple categories, its design is limited by its assumption of an additive relationship between social categories.

In Study 1, I examined perceptions of intersecting social identities and found evidence for a non-additive relationship among them. In Study 2, I was interested in 
investigating the social cognitive processes that occur when perceiving intersecting social identities. Therefore, Study 2's main goal is to directly tests the possibility a nonadditive relationship in multiple category activation using a social cognitive approach within the framework of intersectionality. 


\section{CHAPTER 4}

\section{STUDY 2: INTERSECTIONALITY AND MULTIPLE CATEGORY ACTIVATION}

The main goal of Study 2 was to provide a specific and direct test of simultaneous multiple category activation that can detect either an additive or non-additive relationship among social categories. This study is conceptually similar to a study in which the gender and race of the Asian woman were made salient via an ostensible video editing task (Macrae et al., 1995). Accessibility was subsequently measured with a lexical decision task. For the purposes of observing the activation and inhibition of single categories, the study design was sufficient. However, it offered a limited approach to observing multiple category activation as it allowed for only an additive model of multiple category activation to be detected. Multiple category activation could only have been observed if recognition of race-related words and gender-related words was equally fast. An intersectionality approach to this study hypothesizes that while this may be an option, there is also an alternative. Following the "both/and approach", intersectionality theory posits that the combination of race and gender may result in a unique category that cannot be observed simply by adding its components. In order to have detected this type of category activation, it would have been necessary to include an Asian woman category prime and Asian woman-related words.

Therefore, I added another condition in which both gender and race were made salient through a scholarship evaluation task. Subsequently, participants completed a lexical decision task to assess category activation. The critical words varied based on the stereotypicality associated with race, gender, or the both race and gender. My primary hypotheses are dependent upon the replication of the main findings from the Macrae et al. 
(1995) study. Thus, I hypothesized when primed with race, mean response time to racerelated words would be quicker than mean response time to gender-related words. Likewise, when primed with gender, mean response time to gender-related words would be quicker relative to mean response time to race-related words. If those two conditions were met, then I would investigate the possibility of simultaneous activation of multiple categories. Based on intersectionality theory, two outcomes support multiple category activation. An additive relationship among social categories would be evidenced by equal mean responses times to race-related words and gender-related words. If there is a non-additive relationship among social identities, then mean response times to the combined race and gender stereotype words will be faster relative to mean response times to the other types of words.

\section{Method}

\section{Participants}

Like in Study 1, participants were recruited at Temple University via an online participant sign-up system to participate in an ostensible study about evaluating scholarship applications. One hundred and eighty nine undergraduate students completed the study (134 females; 54 males; 1 unidentified). Much of the sample identified their race as Caucasian (48.7\%). The remainder of the sample identified as African American (26.5\%), Asian American (17.5\%), Hispanic American (4.2\%), and Other (2.6\%). One person did not identify race $(.5 \%)$. The mean age of the sample was 20.5 years-old $(S D=$ 3.2 years). All participants received partial course credit in exchange for their participation. 


\section{Procedure}

In Study 2, I employed a one factor design in order to examine the potential for simultaneous activation of social categories following a non-additive pattern.

Participants were randomly assigned to one of four conditions in which they were asked to evaluate a Temple University student's ostensible scholarship application: gender salient, race salient, race and gender salient, or the control condition. Participants were greeted by a white, female research assistant who reviewed the consent form and provided instructions for the study. They completed the study in groups of up to four individuals. The independent variable was manipulated through the scholarship organization in the scholarship application evaluation task: National Organization of Women (NOW; gender), National Association for the Advancement of Colored People (NAACP; race), National Council of Negro Women (NCNW; race and gender), and American College Student Association (ACSA; control). After evaluating the student's scholarship application, participants completed a lexical decision task in order to measure category activation. The primary dependent variable was mean lexical decision latency to each type of stereotype word.

\section{Materials}

Scholarship Evaluation Task. Participants evaluated an ostensible Temple University student's application for a scholarship from one of four organizations (See Appendix $\mathrm{C}$ for an example). Other than the scholarship organization, all information that participants received was identical. Neither gender nor race were explicitly mentioned to participants. Participants were told to take as much time as they needed to review the application and then were asked to evaluate it on 6 items (See Appendix D for 
exact wording). These 6 items were included only to uphold the ostensible purpose of the study as a scholarship evaluation study and were not included in any analysis.

Lexical Decision Task. Directly after completing the evaluation task, participants completed a lexical decision task (LDT). It was administered on a Dell desktop computer using Medialab and Direct RT software. Participants were told to complete the task as accurately and quickly as possible. Letters strings were presented in all capital letters Times New Roman 20-point font in the center of the computer screen. If the letter string presented was a word in English, participants were instructed to press the "Z" key with their left index finger. If the letter string presented was a nonword, participants were instructed to press the "2" key on the number keypad with their right index finger.

The words used in the critical trials were based on pretesting with Temple University undergraduate students. First, twenty-five students listed knowledge of the content of stereotypes of women in general, African Americans in general, or African American women. From this sample, 28 traits were selected and an independent sample of students rated the stereotypicality of each on a 7-point rating scale ranging from 0 (not stereotypical) to 6 (very stereotypical). I was interested in identifying stereotypical traits that applied to each group (i.e., African Americans in general, women in general, and African American women), but not the other groups (for an example of the questions, see Appendix E). Therefore, ratings of stereotypicality were made relative to other groups. For instance, I asked "Compared to African American women, how stereotypical is the trait feminine of women in general?". Based on responses to these questions, I chose 4 traits that were stereotypical of each group, but irrelevant to the other two. The words used in the practice block were not pretested. 
Participants completed a practice block in which they were presented with 6 words (chair, January, orange, straight, tread, yogurt), and 6 nonwords (dreat, hirac, gearno, jaryanu, rugtoy, thatrigs). The practice block was followed by 48 study trials. All of the nonwords were pronounceable anagrams of the actual words used in the LDT. There were a total of 12 critical trials, in which 4 words were related to stereotypes of women, but not to stereotypes of African Americans or African American women (feminine, nurturing, pretty, romantic); 4 words were related to stereotypes of African Americans, but not to stereotypes of women or African American women (aggressive, athletic, criminal, rhythmic); and 4 words were related to stereotypes of African American women, but not to stereotypes of women or African Americans in general (curvy, loud, proud, strong).

Participants were also presented with 12 filler words (names of countries): Argentina, Albania, Croatia, Cuba, Finland, Laos, Norway, Peru, Poland, Romania, Russia, and Spain. The 24 nonwords used in the LDT were pronounceable anagrams of the filler and critical words and included: abailan, acub, againturn, asevergigs, asirus, catoari, clanirim, cleathit, doul, fiemenin, flandin, inspa, landop, manortic, nayrow, pettry, peur, richmyth, rignunrut, roamani, rodup, ruvcy, saol, and trongs.

Letter strings were randomly presented to each participant. The computer recorded the lexical decisions and response times (in milliseconds) of each participant. If participants did not respond within $1500 \mathrm{~ms}$, the lexical decision was recorded as incorrect. Response times on the lexical decision task were assumed to reflect the relative accessibility of the stereotype under investigation (Dovidio, Evans, \& Tyler, 1986; Macrae, Stangor, \& Milne, 1994; Perdue \& Gurtman, 1990). Specifically, faster 
response times were interpreted as being indicative of increased category accessibility relative to slower response times.

\section{Results}

Participants made incorrect classifications at a much higher rate than is typically reported in the literature using the LDT; mean error rates are typically reported as being < $1 \%$ for critical and nonword trials (e.g., Macrae et al., 1995). For the entire sample, the mean error rate was $8.8 \%$ for the critical trials, $15.4 \%$ for filler words, and $33.8 \%$ for nonwords. Therefore, I calculated mean lexical decision latencies based only on correct classification responses. In order to exclude those participants who did not understand or take the LDT seriously, I excluded participants whose error rates were greater than $20 \%$ for the critical trials, nonword trials, and/or the filler word trials. All further statistical analyses are based on a sample of 80 participants, unless otherwise stated. For this sample, mean error rates were reduced to: $7.0 \%$ for critical words, $8.7 \%$ for filler words, and $8.3 \%$ for nonwords.

The primary dependent measure of interest was mean time taken by participants to classify the different categories of stereotype words as words in English correctly. I hypothesized that congruency between category prime and stereotype-related word in the LDT would lead to faster mean lexical decision latencies on the LDT. Specifically, participants in the women prime condition will respond fastest to words related to stereotypes of women in general relative to the other types of words in the LDT. Participants in the African American prime condition will respond fastest to words related to stereotypes of African Americans in general relative to the other types of words in the LDT. For the African American woman prime, two different patterns of results 
would support my hypothesis. An additive pattern of activation would be supported if participants in the African American women prime condition respond equally fast to both women stereotype words and African American stereotype words. A non-additive pattern would be supported if participants in the African American women prime condition respond fastest to words related to stereotypes of African American women relative to the other types of words in the LDT.

To test my primary hypothesis that stereotype-related words would be more accessible after exposure to the congruent category prime, I submitted lexical decision latencies to a 4 (prime: African American or women or African American women or control) X 3 (stereotype word type: African American or women or African American women) mixed design ANOVA with repeated measures on the second factor (See Table 5). I performed Mauchly's test, which indicated that the assumption of sphericity had been violated $\left(\chi^{2}(2)=17.60, p<.01\right)$; therefore degrees of freedom were corrected using Greenhouse-Geisser estimates of sphericity $(\varepsilon=.83)$. There was no significant main effect of prime (i.e., race salient, gender salient, race and gender salient, or neither race nor gender salient), $F(3,76)=1.76, p=.16, \eta^{2}=.02$. There was a main effect of type of stereotype word (i.e., African American stereotype-related, women stereotype-related, or African American women stereotype-related) on mean lexical decision latencies, $F(1.65,125.71)=24.87, p<.001, \eta^{2}=.25$. Consistent with my hypothesis, analysis showed that there was a significant interaction between type of word and condition, $F(4.96,125.71)=2.80, p=.02, \eta^{2}=.10$. However, follow-up tests revealed that this interaction was not consistent with either of the hypothesized patterns of results. 
I conducted simple effects analyses and applied a Bonferroni correction. The simple effect word type for the African American prime revealed that mean lexical decision latencies were different across the three types of stereotype words, $F(1.51,27.10)$ $=7.72, p<.05, \eta^{2}=.30$. A contrasts analysis was conducted to examine the specific mean differences among the three word types within each condition. A Bonferonni correction was applied to all contrast analyses. For the African American prime condition, mean lexical decision latencies for African American women stereotype words were faster than mean lexical decision latencies for African American stereotype words, $t(76)=-3.28, p<.05$ and women stereotype words, $t(76)=2.85, p<.05$. There was no difference in mean lexical decision latencies between African American stereotype words and women stereotype words, $t(76)=.75, n s$, for the African American prime condition.

Simple effects analyses of word type for the women prime condition, $\left(F(1.88,33.86)=2.05, n s, \eta^{2}=.10\right)$ and the African American women prime condition $\left(F(1.62,37.28)=2.55, n s, \eta^{2}=.10\right)$ revealed that mean lexical decision latencies were the same across the three types of stereotype words. Contrast analysis revealed that there were no differences in the mean time taken by participants to classify the different types of words as words for the women prime condition or African American women prime condition.

Unexpectedly, the simple effect word type for the control prime also revealed that mean lexical decision latencies were different across the three types of stereotype words, $F(1.35,23.00)=15.03, p<.05, \eta^{2}=.47$. For the control condition, participants had faster mean lexical decision latencies for African American stereotype words relative to women stereotype words, $t(76)=2.47, p<.05$. Participants responded faster to African 
American women stereotype words, relative to African American stereotype words, $t(76)$ $=-5.26, p<.05$, and women stereotype words, $t(76)=5.78, p<.05$, in the control condition.

\section{Discussion}

The first goal of Study 2 was to replicate past findings (e.g., Macrae et al., 1995) demonstrating single category activation after priming and then to show that multiple categories can also be simultaneously activated without adhering to an additive pattern. Interpreting the results of Study 2 is dependent on successful category priming via the scholarship application evaluation task. However, the prime was not effective. Specifically, I hypothesized that when exposed to the gender prime (i.e., NOW application) that participants would respond more quickly to gender stereotype words relative to other types of words on the lexical decision task and that when exposed to the race prime (i.e., NAACP application) that participants would respond more quickly to race stereotype words relative to the other types of words on the lexical decision task. Neither of these hypotheses was supported in the present study. While these findings do not necessarily eliminate the possibility of simultaneous multiple category activation, employment of a successful single category prime is a prerequisite to conducting a proper investigation of multiple category activation. Therefore, it is extremely important to identify why this occurred in order to remedy these issues.

One reason that I may not have found the anticipated results is because the words used in the lexical decision task were not related to stereotypes of each group (i.e., African Americans in general, women in general, and African American women), or that there was overlap between groups in the stereotypicality of the words used. This 
explanation seems unlikely, given that the words used in the lexical decision task were pretested. I found that each set of stereotype words was perceived only to be related to the specific group among the current sample.

A more plausible explanation for the failure to find the anticipated results is related to the priming technique. Several factors may have influenced the failure of the priming technique employed in the current study. First of all, the prime was very subtle. Despite the fact that the name of the organization was in several places including the top of the packet that participants were given, they may not have attended to it. The priming technique used in Macrae et al.'s (1995) study was also very subtle, as participants only viewed a 15 second video clip. However, it may have worked even if participants were not aware of the prime (e.g., Bargh, Chen, \& Burrows, 1996). Priming is contingent on a strong association between the prime and the observed outcome. Because putting on lipstick is strongly associated with being a woman and eating with chopsticks is strongly associated with being Asian, the priming technique's subtly was not problematic. The priming technique used in the current study was dependent on participants' knowledge of the primary population of people served by each organization. If, for instance, participants did not know that the primary population of people served by the NAACP was African Americans, then it would not have worked regardless of participants' awareness. In the future, I would ensure that participants were made explicitly aware of the primary population served by each organization to increase the likelihood of successful priming.

The second factor that may have influenced the priming technique's failure could be the extremely high error rates on the lexical decision task. Participants may not have 
been clear about the goal of the task. While this seems unlikely, given that participants were given instructions both verbally from the experimenter and via written instructions on the computer screen, I would modify the verbal and written instructions to provide more clarity about the lexical decision task's goal in the future. I would also make other procedural changes, such as dividing the practice and study trials of the lexical decision task by adding a screen reminding participants of the purpose of the task. Based on recent research utilizing the lexical decision task (Christopherson \& Ferraro, 2009), I might also added a $1500 \mathrm{~ms}$ fixation point at the beginning of each trial to guarantee that participants are prepared for the subsequent trial. Lastly, I would change the protocol to motivate participants to correctly classify the letter strings as words or nonwords. When participants respond correctly a green $\mathrm{O}$ will appear for $150 \mathrm{~ms}$, and when participants respond incorrectly a red X will appear in the center of the screen for $1500 \mathrm{~ms}$.

Together the modifications to Study 2's design and protocol should maximize participants' understanding of the lexical decision task's goal and minimize their incorrect classification of letter strings as words and nonwords, and provide sufficient conditions for the singular category prime (i.e., race prime and gender prime) to work. In that case, I will be able to examine the possibility of multiple category activation (i.e., race and gender prime) that does not follow an additive pattern. 


\section{CHAPTER 5}

\section{GENERAL DISCUSSION}

The overarching goal of this set of studies was to test the theory of intersectionality directly by investigating perceptions of multiple social identities and category activation, using quantitative methods traditionally employed in social psychological research. Study 1's major finding was that intersecting social identities accounted for nearly twice the amount of variance in overall impression ratings than did singular identities. In addition, Study 1 examined how different combinations of three social identities based on race, gender, and sexual orientation affected evaluations of overall impression and personality ratings. Overall impression ratings differed depending on the combination of target race, target gender, and target sexual orientation. The combination of these three social identities also led to differences in personality ratings of honesty, emotionality, and openness. Notably, ratings for the personality dimensions of extraversion, agreeableness, and conscientiousness did not differ across condition. These findings demonstrate that, in some cases, perceptions of individuals differ and are dependent upon the composition of specific social identities; while in others, perceptions are identical and independent of the target's social identities.

The goal of Study 2 was to demonstrate the potential for simultaneous activation of two categories based on race and gender in a manner that does not limit the pattern of activation to one that relies on additivity. Participants were primed with a race category, a gender category, or a combined race and gender category via a supposed scholarship application evaluation task. A lexical decision task using words related to stereotypes of African Americans in general (race category), women in general (gender category), and 
African American women (combined racial and gender category) was used to measure relative category accessibility. Unfortunately, the priming technique employed in Study 2 did not work as hypothesized. Participants did not respond faster to gender-related words relative to other types of words after exposure to the gender prime, nor did participants exposed to the race prime respond faster to race-related words relative to other types of words. Because these primes were not effective, conclusions about the pattern of simultaneous activation of multiple categories (i.e., race and gender) could not be drawn. In the future, procedural changes will be made to increase the likelihood of successful category priming. Together, these two studies form just the beginning of potential research pursuits that utilize intersectionality to study social identities.

As several psychologists have recently noted, intersectionality theory can potentially reframe how psychologists approach the examination of social identities at every step of the research process (Bowleg, 2008; Cole, 2009; Warner, 2008). While intersectionality theory originated with feminist and critical race scholars, it can be used to inform mainstream social psychological understandings of social identity. Reframing research questions using intersectionality theory can inform research about social identities that employs a traditional social psychological methodology. In particular, the interpretation of Study 1's findings draws attention not only to the differences that were found, but also to the similarities in the dependent variables that were found across conditions. The interpretation of null findings in Study 1 emphasizes commonalities among individuals with different intersecting social identities. Historically, psychologists have focused on finding and understanding differences among individuals. Utilizing intersectionality theory to inform psychological understandings of social identities 
accentuates similarities and points of connection. Intersectionality theory can easily be seen as emphasizing the differences among individuals in its focus on the intersection of particular social identities. Rather than being seen as divisive by reducing identities into increasingly specific categories, intersectionality theory can be viewed as unifying by drawing attention to individuals' commonalities. Future research to test the tenets of intersectionality theory must be conducted in order to understand the factors that may cause perceived similarities and differences among individuals.

\section{Future Research Directions}

Intersectionality theory is particularly useful in highlighting identity status's role in examining intersecting social identities. Past social psychological research has focused on ingroup and outgroup status in determining how group members are evaluated and perceived (Crisp \& Hewstone, 2007). While this area of research has been fruitful, intersectionality provides theoretical rationale for expanding the focus to encompass the subordinate or dominant status of social identities. It is time that social psychologists recognize the differences and similarities between social identities based on their position in the social hierarchy. Doing so will allow a greater understanding of how social identities are processed and evaluated.

In addition, future research should focus on the role of perceiver social identities, as well as the interaction between target social identities and perceiver social identities. This area of research is ripe for the potential to yield a rich body of knowledge that combines distinct perspectives on social identity. For instance, future research could investigate the types of perceiver social identities that affect perceptions (e.g., race, gender, sexual orientation) in a similar manner to Study 1. It is also extremely important 
to measure other characteristics of both targets and perceivers. As researchers, we should not rely on using social categories as explanatory constructs. Instead, future research must focus on measuring constructs that are pertinent to explaining factors affecting social perception. Certainly, the role ingroup and outgroup status has been studied in the past, but the options are much more vast than past research would suggest. Depending on the research question, factors that might be interesting to investigate include perceiver personality traits, need for cognition, level of prejudice, and identity importance.

Intersectionality theorists also can benefit from employing quantitative methods traditionally used in social cognitive research to study social identity and to expand their focus to social categorization. Utilizing these methods has the potential to increase the scientific rigor of intersectionality research. In addition, this research will provide the types of quantitative data that social psychology typically relies on to examine the processes of social perception and categorization. In doing so, it may bring greater legitimacy to intersectionality in the eyes of social psychologists who have traditionally studied social identity. While the number of identities able to be examined using quantitative methods is limited, the benefits of using this methodology are great. Used together, intersectionality theory and social cognitive methods can provide scholars with a set of tools that will lead to a greater understanding of how multiple social categories are processed.

While intersectionality theory can certainly benefit from social psychology's approach to social identity, its utility should not be overstated. We live an increasingly multicultural world and must be aware of the pitfalls of decomposing identity categories into increasingly smaller, more specific categories. Rather than doing so in a haphazard 
manner, we must carefully consider the types of identities that are likely to affect perceptions and experience of intersecting identities. This is dependent not only on the identity type itself, but also situational factors. Increasing attention should be paid to those factors likely to affect the types of multiple identities that emerge as most important in affecting perceptions and experiences. Identity is a dynamic construct that can best be thought of as a process and yet studying social identities using quantitative methods risks reducing identity to a singular and static entity. Future research might address this by using a mixed-methods longitudinal approach to examine intersecting social identities over time, similar to that used by Diamond (2005) to study female sexuality. Without a critical consideration of the meanings of social categories, using intersectionality in psychological research identity risks committing similar mistakes to those that intersectionality scholars claim have plagued understandings of identity.

\section{Concluding Remarks}

As we move through the world, it is easy to notice how we differ from others whom we encounter along the way. Consequently, it is tempting to gravitate toward similar others and to perceive anyone who differs from us along a particular dimension as being someone with whom we have nothing in common. Intersectionality theory demands a critical analysis of social identities -- of the social, historical, and institutional structures that contexualize and situate them within a hierarchy of power relations. Importantly, it also stipulates recognition of our common humanity and the establishment of points of connection with those who have different intersecting identities. This certainly is a challenging task and a vision that is not shared by all, but one that I believe we must work toward achieving. 


\section{REFERENCES CITED}

Allen, V. L., \& Wilder, D. A. (1979). Group categorization and attribution of belief similarity. Small Group Behavior, 10, 73-80.

Allport, G. W. (1954). The nature of prejudice. Cambridge, MA: Addison-Wesley. Anderson, N. H. (1966). Component ratings in impression formation. Psychonomic Science, 6, 279-280.

Anderson, N. H. (1971). Two more tests against change in meaning in adjective combinations. Journal of Verbal Learning and Verbal Behavior, 10, 75-85.

Anderson, N. H., \& Lampel, A. M. (1965). Effect of context on ratings of personality traits. Psychonomic Science, 3, 433-434.

Asch, S. E. (1946). Forming impressions of personality. The Journal of Abnormal and Social Psychology, 41, 258-290.

Ashton, M. C., \& Lee, K. (2008). The prediction of honesty-humility-related criteria by the HEXACO and Five-Factor models of personality. Journal of Research in Personality, 42, 1216-1228.

Ayres, I., \& Siegelman, P. (2001). Gender and race discrimination in retail car negotiations. In I. Ayres (Ed.), Pervasive prejudice? Unconventional evidence of race and gender discrimination (pp. 19-44). Chicago, IL: University of Chicago Press.

Baca Zinn, M \& Thornton Dill, B. (1996). Theorizing difference from multiracial feminism. Feminist Studies, 22, 321-333. 
Bargh, J. A., Chen, M., \& Burrows, L. (1996). Automaticity of social behavior: Direct effects of trait construct and stereotype activation on action. Journal of Personality and Social Psychology, 71, 230-244.

Bodenhausen, G. V. (2010). Diversity in the person, diversity in the group: Challenges of identity complexity for social perception and social interaction. European Journal of Social Psychology, 40, 1-16.

Bodenhausen, G. V., \& Macrae, C. N. (1998). Stereotype activation and inhibition. In R. S. Wyer, Jr. (Ed.), Stereotype Activation and Inhibition: Advances in Social Cognition (pp. 1-52). Mahwah, NJ: Lawrence Erlbaum Associates.

Bonilla-Silva, E. (1997). Rethinking racism: Towards a structural interpretation. American Sociological Review, 62, 465-480.

Borkenau, P., \& Liebler, A. (1992). Trait inferences: Sources of validity at zero acquaintance, Journal of Personality and Social Psychology, 62, 645-657.

Bowleg, L. (2008). When black + lesbian + women $\neq$ black lesbian woman: The methodological challenges of qualitative and quantitative intersectionality research. Sex Roles, 59, 312-325.

Brewer, M. B. (1979). In-group bias in the minimal intergroup situation: a cognitivemotivational analysis. Psychological Bulletin, 86, 307-324.

Brewer, M. B., Ho, H., Lee, J., \& Miller, N. (1987). Social identity and social distance among Hong Kong school children. Personality and Social Psychology Bulletin, $13,156-165$.

Burgess-Proctor, A. (2006). Intersections of race, class, gender, and crime: Future directions for feminist criminology. Feminist Criminology, 1, 27-47. 
Burke, P. J. (1980). The self: Measurement implications from a symbolic interactionist perspective. Social Psychology Quarterly, 43, 18-29.

Carver, C. S., Gannellen, R. J., Froming, W. J., \& Chambers, W. (1983). Modeling: An analysis in terms of category accessibility. Journal of Experimental Social Psychology, 19, 403-428.

Cerulo, K. A. (1997). Identity construction: New issues, new directions. Annual Review of Sociology, 23, 385-409.

Chaplin, W. F., Phillips, J. B., Brown, J. D., Clanton, N. R., \& Stein, J. L. (2000). Handshaking, gender, personality, and first impressions. Journal of Personality and Social Psychology, 79, 110-117.

Chen, M., \& Bargh, J. A. (1997). Nonconscious behavioral confirmation processes: The self-fulfilling consequences of automatic stereotype activation. Journal of Experimental Social Psychology, 33, 541-560.

Christopherson, K. M., \& Ferraro, F. R. (2009). Primed lexical decision task in fearful and nonfearful individuals. The Journal of Psychology, 143, 267-278.

Chong, V., Um, K., Hahn, M., Pheng, D., Yee, C., \& Auerswald, C. (2009). Toward an intersectional understanding of violence and resilience: An exploratory study of young Southeast Asian men in Alameda and Contra Costa County, California. Aggression and Violent Behavior, 14, 461-469.

Cislo, A. M. (2008). Ethnic identity and self esteem: Contrasting Cuban and Nicaraguan young adults. Hispanic Journal of Behavioral Sciences, 30, 230-250.

Cole, E. R. (2008). Coalitions as a model for intersectionality: From practice to theory. Sex Roles, 59, 443-453. 
Cole, E. R. (2009). Intersectionality and research in psychology. American Psychologist, 64, 170-180.

Collins, P. H. (1991). Black feminist thought: Knowledge, consciousness, and the politics of empowerment. New York: Routledge.

Collins, P. H. (2000). Black feminist thought: Knowledge, consciousness, and the politics of empowerment ( $2^{\text {nd }}$ ed.). New York: Routledge.

Crenshaw, K. (1991). Mapping the margins: Intersectionality, identity politics, and violence against women. Stanford Law Review, 43, 1241-1299.

Crisp, R. J., \& Hewstone, M. (1999). Differential evaluation of crossed category groups: Patterns, processes, and reducing intergroup bias. Group Processes and Intergroup Relations, 2, 303-333.

Crisp, R. J., \& Hewstone, M. (2000). Crossed categorization and intergroup bias: The moderating roles of intergroup and affective context. Journal of Experimental Social Psychology, 36, 357-383.

Crisp, R. J., \& Hewstone, M. (2001). Multiple categorization and implicit intergroup bias: Differential category dominance and the positive-negative asymmetry effect. European Journal of Social Psychology, 31, 45-62.

Crisp, R. J., Hewstone, M., \& Rubin, M. (2001). Does multiple categorization reduce intergroup bias? Personality and Social Psychology Bulletin, 27, 76-89.

Christopherson, K. M., \& Ferraro, F. R. (2009). Primed lexical decision task in fearful and nonfearful individuals. The Journal of Psychology, 143, 267-278.

Davies, M. (2004). Correlates of negative attitudes toward gay men: Sexism, male role norms, and male sexuality. The Journal of Sex Research, 41, 259-266. 
Devine, P. G. (1989). Stereotypes and prejudice: Their automatic and controlled components. Journal of Personality and Social Psychology, 56, 5-18.

Diamond, L. (2005). A new view of lesbian subtypes: Stable vs. fluid identity trajectories over an 8-year period. Psychology of Women Quarterly, 29, 119-128.

Diehl, M. (1990). The minimal group paradigm: Theoretical explanations and empirical findings. In W. Stroebe \& M. Hewstone (Eds.), European review of social psychology (Vol. 1, pp. 263-292). Chichester, UK: Wiley.

Dovidio, J. F., \& Gaertner, S. L. (1993). Stereotypes and evaluative intergroup bias. In D. M. Mackie \& D. L. Hamilton (Eds.), Affect, cognition, and stereotyping: Interactive processes in group perception (pp. 167-193). San Diego, CA: Academic Press.

Dovidio, J. F., Evans, N., \& Tyler, R. B. (1986). Racial stereotypes: The contents of their cognitive representations. Journal of Experimental Social Psychology, 22, 22-37.

Eagly, A. H. (1987). Sex difference in social behavior: A social-role interpretation. Hillsdale, NJ: Erlbaum.

Eagly, A. H., Mladinic, A. (1989). Gender stereotypes and attitudes toward women and men. Personality and Social Psychology Bulletin, 15, 543-558.

Eagly, A. H., \& Wood, W. (1991). Explaining sex differences in social behavior: A metaanalytic perspective. Personality and Social Psychology Bulletin, 17, 306-315.

Erdley, C. A., \& D’Agostino, P. R. (1988). Cognitive and affective components of automatic priming affects. Journal of Personality and Social Psychology, 54, 741747. 
Fazio, R., H., Powell, M. C., \& Herr, P. M. (1983). Toward a process model of the attitude-behavior relation: Accessing one's attitude upon mere observation of the attitude object. Journal of Personality and Social Psychology, 44, 723-735.

Fiske, S. T., \& Taylor, S. E. (2008). Social cognition: From brains to culture $\left(3^{\text {rd }}\right.$ ed.). New York: McGraw-Hill.

Freeman, J. B., Ambady, N., Rule, N. O., \& Johnson, K. L. (2008). Will a category cue attract you? Motor output reveals dynamic competition across person construal. Journal of Experimental Psychology: General, 137, 673-690.

Gay, C., \& Tate, K. (1998). Doubly bound: The impact of gender and race on the politics of black women. Political Psychology, 19, 169-184.

Gilbert, D. T., \& Hixon, G. J. (1991). The trouble of thinking: Activation and application of stereotypic beliefs. Journal of Personality and Social Psychology, 60, 509-517.

Gillum, T. L. (2007). “How do I view my sister?” Stereotypic view of African American women and their potential to impact intimate partnerships. Journal of Human Behavior in the Social Environment, 15, 347-366.

Goode-Cross, D. T., \& Good, G. E. (2009). Managing multiple-minority identities: African American men who have sex with men at predominantly white universities. Journal of Diversity in Higher Education, 2, 103-112.

Goody, J. (1997). Boys don’t cry: Masculinities, fear of crime and fearlessness. British Journal of Criminology, 37, 401-418.

Gosling, S. D., Ko, S. J., Mannarelli, T., \& Morris, M. E. (2002). A room with a cue: Personality judgments based on offices and bedrooms. Journal of Personality and Social Psychology, 82, 379-398. 
Gosse, D., Parr, M., \& Allison, J. (2008). Researching the halted paths of male primary school teacher candidates. The Journal of Men's Studies, 16, 57-68.

Greenwood, R. M., \& Christian, A. (2008). What happens when we unpack the invisible knapsack? Intersectional political consciousness and inter-group appraisals. Sex Roles, 59, 404-417.

Hall, N. R., \& Crisp, R. J. (2005). Considering multiple criteria for social categorization can reduce intergroup bias. Personality and Social Psychology Bulletin, 10, 14351444.

Hamilton, D. L., \& Zanna, M. P. (1974). Context effects in impression formation: Changes in connotative meaning. Journal of Personality and Social Psychology, $29,649-654$

Heilman, M. E., Wallen, A. S., Fuchs, D., \& Tamkins, M. M. (2004). Penalties for success: Reactions to women who succeed at male gender-typed tasks. Journal of Applied Psychology, 89, 416-427.

Helms, J. E., Jernigan, M., \& Mascher, J. (2005). The meaning of race in psychology and how to change it: A methodological perspective. American Psychologist, 60, 2736.

Herr, P. M., Sherman, S. J., Fazio, R. H. (1983). On the consequences of priming: Assimilation and contrast effects. Journal of Experimental Social Psychology, 19, $323-340$.

Hewstone, M. (1990). The 'ultimate attribution error'? A review of the literature on intergroup causal attribution. European Journal of Social Psychology, 20,311335. 
Higgins, E. T. (1996). Knowledge activation: Accessibility, applicability, and salience. In E. T. Higgins \& A. W. Kruglanski (Eds.), Social psychology: Handbook of basic principles (pp. 133-168). New York: Guilford.

Higgins, E. T., Rholes, W. S., \& Jones, C. R. (1977). Category accessibility and impression formation. Journal of Experimental Social Psychology, 13, 141-154.

Hulko, W. (2009). The time- and context-contingent nature of intersectionality and interlocking oppressions. Affilia: Journal of Women and Social Work, 24, 44-55.

Kaplan, M. F. (1971). Context effects in impression formation: The weighted average versus the meaning-change formulation. Journal of Personality and Social Psychology, 19, 92-99.

King, D. K. (1988). Multiple jeopardy, multiple consciousness: The context of a black feminist ideology. Signs: Journal of Women in Culture and Society, 14, 42-72.

Kite, M. E., \& Deaux, K. (1987). Gender belief systems: Homosexuality and the implicit inversion theory. Psychology of Women Quarterly, 11, 83-96.

Kite, M. E., \& Whitely, B. E. (1996). Sex differences in attitudes toward homosexual persons, behavior, and civil rights: A meta-analysis. Personality and Social Psychology Bulletin, 22, 336-353.

Krech, D., \& Crutchfield, R. S. (1948). Theory and problems of social psychology. New York: McGraw-Hill.

Kulik, C. T., Roberson, L., \& Perry, E. L. (2007). The multiple-category problem: Category activation and inhibition in the hiring process. Academy of Management Review, 32, 529-548. 
Kunda, Z., \& Thagard, P. (1996). Forming impressions from stereotypes, traits, and behaviors: A parallel-constraint-satisfaction theory. Psychological Review, 103, 284-308.

Lee, K., \& Ashton, M. C. (2004). The HEXACO Personality Inventory: A new measure of the major dimensions of personality. Multivariate Behavioral Research, 39, 329-358.

Lee, K., \& Ashton, M. C. (2006). Further assessment of the HEXACO Personality Inventory: Two new facet scales and an observer report form. Psychological Assessment, 18, 182-191.

Lee, K., Ashton, M. C., Pozzebon, J. A., Visser, B. A., Bourdage, J. S., \& Ogunfowora, B. (2009). Similarity and assumed similarity of personality reports of wellacquainted persons. Journal of Personality and Social Psychology, 96, 460-472.

Lorde, A. (1981). An interview with Audre Lorde: With Adrienne Rich. Signs: Journal of Women in Culture and Society, 6, 713-736.

Mackie, D. M., Hamilton, D. L., Susskind, J., \& Rosselli, F. (1996). Social psychological foundations of stereotype formation. In C. N. Macrae, C. Stangor, \& M. Hewstone (Eds.), Stereotypes and stereotyping (pp. 41-78). New York: Guilford.

Macrae, C. N., Bodenhausen, G. V., \& Milne, A. B. (1995). The dissection of selection in person perception: Executive function and person perception. Journal of Personality and Social Psychology, 76, 200-213.

Macrae, C. N., Stangor, C., \& Milne, A. B. (1994). Activating social stereotypes: A functional analysis. Journal of Experimental Social Psychology, 30, 370-389. 
Madon, S. (1997). What do people believe about gay males? A study of stereotype content and strength. Sex Roles, 37, 663-685.

Martin, L. L. (1986). Set/reset: Use and disuse of concepts in impression formation. Journal of Personality and Social Psychology, 51, 493-504.

Mattis, J. S., Grayman, N. A., Cowie, S., Winston, C., Watson, C., \& Jackson, D. (2008). Intersectional identities and the politics of altruistic care in a low-income, urban community. Sex Roles, 59, 418-428.

McCall, L. (2005). The complexity of intersectionality. Signs: Journal of Women in Culture and Society, 30, 1771-1800.

McConahay, J. G. (1986). Modern racism, ambivalence, and the modern racist scale. In J. F. Dovidio \& S. L. Gaertner (Eds.), Prejudice, discrimination, and racism, San Diego, CA: Academic Press.

McGarty, C. (1999). Categorization in social psychology. London: Sage.

McHale, S. M., Crouter, A. C., \& Whiteman, S. D. (2003). The family contexts of gender development in childhood and adolescence. Social Development, 12, 125-148.

Medin, D. L., \& Ortony, A. (1989). Psychological essentialism. In S. Vosniadou, \& A. Ortony (Eds.), Similarity and analogical reasoning (pp. 179-195). New York: Cambridge University Press.

Miller, N., Urban, L. M., \& Vanman, E. J. (1998). A theoretical analysis of crossed social categorization effects. In C. Sedikides, J. Schopler, \& C. Insko (Eds.), Intergroup cognition and intergroup behavior (pp. 313-419). Hillsdale, NJ: Erlbaum.

Ostrom, T. M., \& Sedikides, C. (1992). Out-group homogeneity effects in natural and minimal groups. Psychological Bulletin, 112, 536-552. 
Page, S., \& Yee, M. (1985). Conception of male and female homosexual stereotypes among university undergraduates. Journal of Homosexuality, 12, 109-118.

Park, B., \& Rothbart, M. (1982). Perception of out-group homogeneity and levels of social categorization: Memory for the subordinate attributes of in-group and outgroup members. Journal of Personality and Social Psychology, 42, 1051-1068.

Perdue, C. W., \& Gurtman, M. B. (1990). Evidence for the automaticity of ageism. Journal of Experimental Social Psychology, 26, 199-216.

Pettigrew, T. W. (1979). The ultimate attribution error: Extending Allport's cognitive analysis of prejudice. Personality and Social Psychology Bulletin, 5, 461-476.

Press, A. L., \& Cole, E. R. (1999). Speaking of abortion: Television and authority in the lives of women. Chicago: University of Chicago Press.

Quattrone, G. A., \& Jones, E. E. (1980). The perception of variability within ingroups and outgroups: Implications for the law of small numbers. Journal of Personality and Social Psychology, 38, 141-152.

Ransford, H. E. (1980). The prediction of social behavior and attitudes. In V. Jeffries, \& H. Ransford (Eds.) Social stratification: A multiple hierarchy approach (pp. 265295). Boston: Allyn \& Bacon.

Reynolds, A. L., \& Pope, R. L. (1991). The complexities of diversity: Exploring multiple oppressions. Journal of Counseling \& Development, 70, 174-180.

Roccas, S., \& Brewer, M. B. (2001). Social identity complexity. Personality and Social Psychology Review, 6, 88-106. 
Rothbart, M., \& Taylor, M. (1992). Category labels and social reality: Do we view social categories as natural kinds? In G. Semin, \& K. Fiedler (Eds.), Language, interaction and social cognition (pp. 11-36). London: Sage.

Shih, M., Pittinsky, T. L., \& Ambady, N. (1999). Stereotype susceptibility: Identity salience and shifts in quantitative performance. Psychological Science, $10,80-83$.

Shook, N. J., \& Fazio, R. H. (2008). Interracial roommate relationships: An experimental field test of the contact hypothesis. Psychological Science, 19, 717-723.

Shorter-Gooden, K, \& Washington, N. C. (1996). Young, black, and female: The challenge of weaving an identity. Journal of Adolescence, 19, 465-475.

Sinclair, L., \& Kunda, Z. (1999). Reactions to a Black professional: Motivated inhibition and activation of conflicting stereotypes. Journal of Personality and Social Psychology, 77, 885-904.

Skowronski, J. J., Carlston, D. E., Isham, J. T. (1993). Implicit versus explicit impression formation: The differing effects of overt labeling and covert priming on memory and impressions. Journal of Experimental Social Psychology, 29, 17-41.

Stangor, C., Lynch, L., Duan, C., \& Glass, B. (1992). Categorization of individuals on the basis of multiple social features. Journal of Personality and Social Psychology, $62,207-218$.

Steele, C. M., \& Aronson, J. (1995). Stereotype threat and the intellectual test performance of African Americans. Journal of Personality and Social Psychology, 69, 797-811. 
Steinbugler, A. C., Press, J. E., \& Johnson Dias, J. (2006). Gender, race, and affirmative action: Operationalizing intersectionality in survey research. Gender \& Society, $20,805-825$.

Stewart, A. J., \& McDermott, C. (2004). Gender in psychology. Annual Review of Psychology, 55, 519-544.

Tajfel, H., Billig, M., Bundy, R. P., \& Falment, C. (1971). Social categorization and intergroup behavior. European Journal of Social Psychology, 1, 149-177.

Tajfel, H., \& Turner, J. C. (1979). An integrative theory of intergroup conflict. In W. G. Austin \& S. Worchel (Eds.), The social psychology of intergroup relations (pp. 33-47). Pacific Grove, CA: Brooks/Cole.

Turner, J. C., Hogg, M. A., Oakes, P. J., Reicher, S. D., \& Wetherell, M. S. (1987). Rediscovering the social group: A self-categorization theory. Oxford, UK: Blackwell.

van Knippenberg, A. V., \& Dijksterhuis, A. (2000). Social categorization and stereotyping: A functional perspective. In W. Stroebe \& M. Hewstone (Eds.), European review of social psychology (Vol. 11, pp. 105-144). Chichester, UK: Wiley.

Van Sell, M., Brief, A. P., \& Schuler, R. S. (1981). Role conflict and role ambiguity: Integration of the literature and directions for future research. Human Relations, $34,43-71$.

Warner, L. R. (2008). A best practices guide to intersectional approaches in psychological research. Sex Roles, 59, 454-463. 
Wilder, D. A. (1978a). Homogeneity of jurors: The majority's influence depends upon their perceived independence. Law and Human Behavior, 2, 363-376.

Wilder, D. A. (1978b). Perceiving persons as a group: Effects on attributions of causality and beliefs. Social Psychology, 1, 12-23.

Wilder, D. A. (1986). Social categorization: Implications for creation and reduction of intergroup bias. In L. Berkowitz (Ed.), Advances in experimental social psychology (Vol. 19, pp. 293-355). New York: Academic Press.

Wyer, R. S., Jr., \& Hartwick, J. (1980). The role of information retrieval and conditional inference processes in belief formation and change. In L. Berkowitz (Ed.). Advances in experimental social psychology, Vol. 13 (pp. 241-284). New York: Academic Press.

Wyer, R.S., \& Watson, S. F. (1969). Context effects in impression formation. Journal of Personality and Social Psychology, 12, 22-23.

Yoder, J. D., \& Aniakudo, P. (1997). "Outsider within” the firehouse: Subordination and difference in the social interactions of African American women firefighters. Gender \& Society, 11, 324-341.

Yoder, J. D., \& Berendsen, L. L. (2001).“Outsider within” the firehouse: African American and white women firefighters. Psychology of Women Quarterly, 25, 2736.

Zaal, M., Salah, T., \& Fine, M. (2007). The weight of the hyphen: Freedom, fusion, and responsibility embodied by young Muslim-American women during a time of surveillance. Applied Development Science, 11, 164-177. 
Table 1. Study 1: Main Effects and Interaction Term Effects by Condition

\begin{tabular}{rcccc}
\hline & $\begin{array}{c}\text { Main } \\
\text { Effects }\end{array}$ & $\begin{array}{c}\text { Interaction } \\
\text { Terms }\end{array}$ & & \\
\cline { 2 - 5 } & $R^{2}$ & $R^{2}$ & $\Delta \mathrm{R}^{2}$ & $F_{\text {Change }}$ \\
\cline { 2 - 5 } Overall Impression & .016 & .040 & .023 & $2.67^{*}$ \\
Personality Traits & & & & \\
Honesty & .014 & .038 & .023 & 2.64 \\
Emotionality & .074 & .113 & .039 & $4.80^{*}$ \\
Extraversion & .004 & .011 & .007 & .79 \\
Agreeableness & .014 & .021 & .007 & .80 \\
Conscientiousness & .002 & .006 & .004 & .48 \\
Openness & .102 & .112 & .009 & 1.15 \\
\hline
\end{tabular}

Note: ${ }^{*}$ indicates statistical significance at $p<.05$ 
Table 2. Study 1: Means and Standard Deviations of Target Ratings by Condition

\begin{tabular}{|c|c|c|c|c|c|c|c|c|}
\hline & \multicolumn{8}{|c|}{ Conditions } \\
\hline & $\begin{array}{c}\text { Caucasian } \\
\text { Heterosexual } \\
\text { Male }\end{array}$ & $\begin{array}{c}\text { Caucasian } \\
\text { Heterosexual } \\
\text { Female }\end{array}$ & $\begin{array}{l}\text { Caucasian } \\
\text { Gay Male }\end{array}$ & $\begin{array}{c}\text { Caucasian } \\
\text { Gay } \\
\text { Female }\end{array}$ & $\begin{array}{c}\text { African } \\
\text { American } \\
\text { Heterosexual } \\
\text { Male }\end{array}$ & $\begin{array}{c}\text { African } \\
\text { American } \\
\text { Heterosexual } \\
\text { Female }\end{array}$ & $\begin{array}{c}\text { African } \\
\text { American } \\
\text { Gay Male }\end{array}$ & $\begin{array}{c}\text { African } \\
\text { American Gay } \\
\text { Female }\end{array}$ \\
\hline Overall Impression & $3.76_{\mathrm{a}, \mathrm{c}}(.64)$ & $3.90_{\mathrm{a}, \mathrm{c}}(.50)$ & $3.87_{\mathrm{a}, \mathrm{c}}(.66)$ & $3.78_{\mathrm{a}, \mathrm{c}}(.63)$ & $4.08_{\mathrm{a}}(.70)$ & $3.89_{\mathrm{a}, \mathrm{c}}(.51)$ & $3.67_{\mathrm{b}, \mathrm{c}}(.58)$ & $3.71_{\mathrm{b}, \mathrm{c}}(.70)$ \\
\hline \multicolumn{9}{|l|}{ Personality Traits } \\
\hline Honesty & $3.16_{\mathrm{a}, \mathrm{b}}(.35)$ & $3.14_{\mathrm{a}, \mathrm{b}}(.31)$ & $3.17_{\mathrm{a}, \mathrm{b}}(.29)$ & $3.28_{\mathrm{a}}(.33)$ & $3.17_{\mathrm{a}, \mathrm{b}}(.30)$ & $3.12_{\mathrm{a}, \mathrm{b}}(.31)$ & $3.07_{\mathrm{b}}(.32)$ & $3.23_{\mathrm{a}, \mathrm{b}}(.26)$ \\
\hline Emotionality & $2.67 \mathrm{a}(.36)$ & $2.96_{b}(.38)$ & $2.95_{\mathrm{b}}(.39)$ & $2.93_{\mathrm{b}}(.37)$ & $2.70 \mathrm{a}(.36)$ & $2.91_{\mathrm{b}}(.26)$ & $3.05_{\mathrm{b}}(.41)$ & $3.01_{\mathrm{b}}(.35)$ \\
\hline Extraversion & $3.58_{\mathrm{a}}(.46)$ & $3.66_{\mathrm{a}}(.47)$ & $3.56_{\mathrm{a}}(.35)$ & $3.60_{\mathrm{a}}(.38)$ & $3.56_{\mathrm{a}}(.43)$ & $3.64_{\mathrm{a}}(.36)$ & $3.68_{\mathrm{a}}(.38)$ & $3.64_{\mathrm{a}}(.35)$ \\
\hline Agreeableness & $3.39 \mathrm{a}(.51)$ & $3.30_{\mathrm{a}}(.41)$ & $3.36_{\mathrm{a}}(.37)$ & $3.33_{\mathrm{a}}(.45)$ & $3.24_{\mathrm{a}}(.43)$ & $3.21_{\mathrm{a}}(.51)$ & $3.19_{\mathrm{a}}(.49)$ & $3.30_{\mathrm{a}}(.37)$ \\
\hline Conscientiousness & $3.42_{\mathrm{a}}(.49)$ & $3.44_{\mathrm{a}}(.39)$ & $3.35_{\mathrm{a}}(.37)$ & $3.41_{\mathrm{a}}(.41)$ & $3.34_{\mathrm{a}}(.36)$ & $3.42_{\mathrm{a}}(.39)$ & $3.43_{\mathrm{a}}(.33)$ & $3.38_{\mathrm{a}}(.41)$ \\
\hline Openness & $3.00_{a, b, c, d}(.42)$ & $3.01_{\mathrm{a}}(.31)$ & $3.21_{\mathrm{b}, \mathrm{c}, \mathrm{d}}(.26)$ & $3.31_{\mathrm{b}, \mathrm{c}, \mathrm{d}}(.32)$ & $2.96_{a}(.34)$ & $3.08_{\mathrm{a}, \mathrm{b}, \mathrm{d}}(.30)$ & $3.12_{\mathrm{a}, \mathrm{b}, \mathrm{c}, \mathrm{d}}(.31)$ & $3.23_{\mathrm{a}, \mathrm{b}, \mathrm{c}, \mathrm{d}}(.37)$ \\
\hline
\end{tabular}

Note: Matching subscript indicates no significant mean difference between conditions 
Table 3. Study 1: Mean Target Ratings and Standard Deviations by Participant Race and Target Race

\begin{tabular}{|c|c|c|}
\hline \multirow[t]{2}{*}{$\begin{array}{c}\text { Dependent Variable by } \\
\text { Participant Race }\end{array}$} & \multicolumn{2}{|c|}{ Target Race } \\
\hline & African American & Caucasian \\
\hline \multicolumn{3}{|l|}{ Overall Impression } \\
\hline African American & $3.86(.73)$ & $3.79(.67)$ \\
\hline Caucasian & $3.84(.66)$ & $3.79(.55)$ \\
\hline \multicolumn{3}{|l|}{ Honesty } \\
\hline African American & $3.10(.33)$ & $3.21(.32)$ \\
\hline Caucasian & $3.18(.29)$ & $3.20(.33)$ \\
\hline \multicolumn{3}{|l|}{ Emotionality } \\
\hline African American & $2.90(.38)$ & $2.83(.39)$ \\
\hline Caucasian & $2.91(.35)$ & $2.87(.39)$ \\
\hline \multicolumn{3}{|l|}{ Extraversion } \\
\hline African American & $3.64(.38)$ & $3.61(.36)$ \\
\hline Caucasian & $3.65(.37)$ & $3.60(.41)$ \\
\hline \multicolumn{3}{|l|}{ Agreeableness } \\
\hline African American & $3.24(.46)$ & $3.47(.38)$ \\
\hline Caucasian & $3.26(.45)$ & $3.35(.42)$ \\
\hline \multicolumn{3}{|l|}{ Conscientiousness } \\
\hline African American & $3.33(.38)$ & $3.44(.44)$ \\
\hline Caucasian & $3.43(.35)$ & $3.42(.41)$ \\
\hline \multicolumn{3}{|l|}{ Openness } \\
\hline African American & $3.09(.33)$ & $3.19(.33)$ \\
\hline Caucasian & $3.10(.35)$ & $3.11(.36)$ \\
\hline
\end{tabular}


Table 4. Study 1: Mean Target Ratings and Standard Deviations by Participant Gender and Target Gender

\begin{tabular}{|c|c|c|c|}
\hline \multicolumn{2}{|c|}{$\begin{array}{l}\text { Dependent Variable by } \\
\text { Participant Gender }\end{array}$} & \multicolumn{2}{|c|}{ Target Gender } \\
\hline & & Female & Male \\
\hline \multicolumn{4}{|l|}{ Overall Impression } \\
\hline & Female & $3.87(.62)$ & $3.92(.59)$ \\
\hline & Male & $3.72(.55)$ & $3.73(.76)$ \\
\hline \multicolumn{4}{|l|}{ Honesty } \\
\hline & Female & $3.23(.28)$ & $3.17(.30)$ \\
\hline & Male & $3.12(.34)$ & $3.12(.35)$ \\
\hline \multicolumn{4}{|l|}{ Emotionality } \\
\hline & Female & $2.94(.35)$ & $2.82(.40)$ \\
\hline & Male & $2.98(.33)$ & $2.90(.45)$ \\
\hline \multicolumn{4}{|l|}{ Extraversion } \\
\hline & Female & $3.65(.40)$ & $3.65(.41)$ \\
\hline & Male & $3.60(.37)$ & $3.54(.40)$ \\
\hline \multicolumn{4}{|l|}{ Agreeableness } \\
\hline & Female & $3.32(.42)$ & $3.32(.47)$ \\
\hline & Male & $3.22(.47)$ & $3.22(.44)$ \\
\hline \multicolumn{4}{|l|}{ Conscientiousness } \\
\hline & Female & $3.39(.41)$ & $3.40(.40)$ \\
\hline & Male & $3.46(.38)$ & $3.38(.40)$ \\
\hline \multicolumn{4}{|l|}{ Openness } \\
\hline & Female & $3.14(.35)$ & $3.11(.30)$ \\
\hline & Male & $3.20(.34)$ & $3.03(.42)$ \\
\hline
\end{tabular}


Table 5. Study 2: Mean Lexical Decision Latencies in Milliseconds as a Function of Prime and Trait Stereotypicality

\begin{tabular}{lccc}
\hline & \multicolumn{3}{c}{ Trait Type } \\
\cline { 2 - 4 } Prime & $\begin{array}{c}\text { African } \\
\text { Americans }\end{array}$ & Women & $\begin{array}{c}\text { African American } \\
\text { Women }\end{array}$ \\
\hline African American $(n=19)$ & 658 & 681 & 587 \\
Women $(n=19)$ & 689 & 690 & 643 \\
African American Women $(n=24)$ & 648 & 677 & 617 \\
Control $(n=24)$ & 713 & 794 & 597 \\
\hline
\end{tabular}


Figure 1. Study 1: Mean Ratings of Openness by Participant Gender and Target Gender

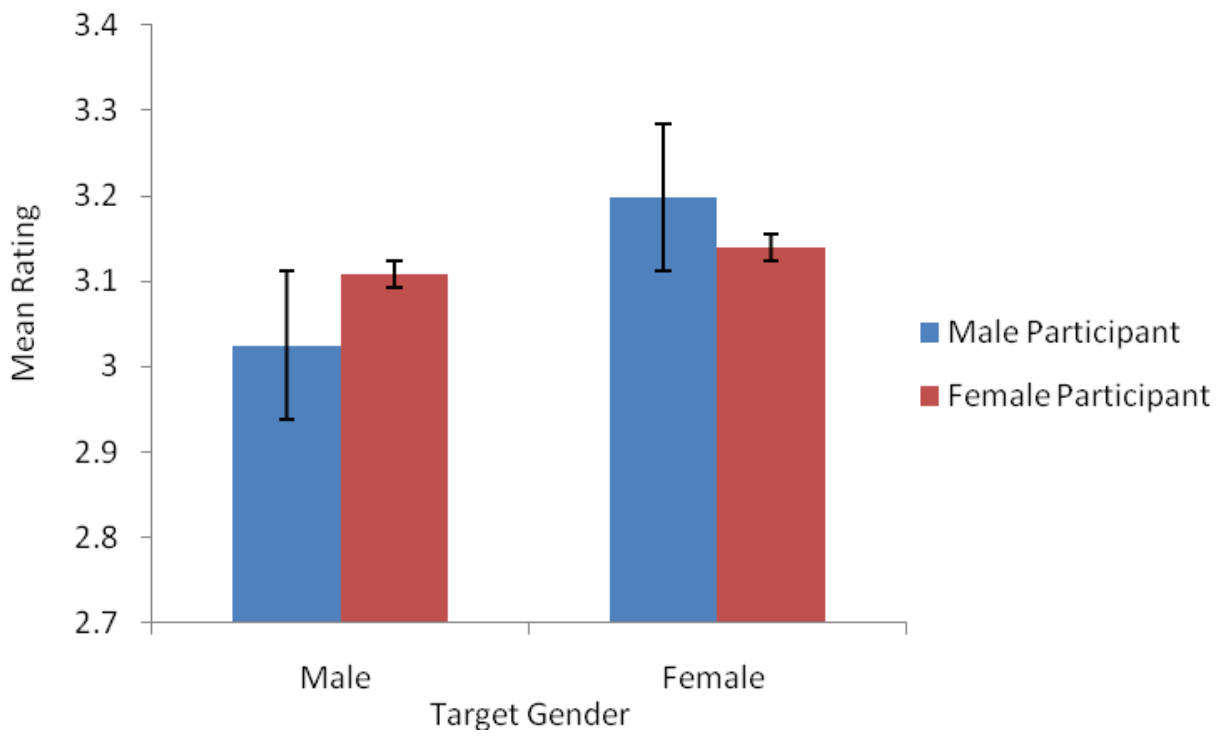

Note: Error bars represent standard error 


\section{APPENDICES}




\section{APPENDIX A}

\section{STUDY 1: HOUSING AND RESIDENCE LIFE ROOMMATE SURVEY}

\section{Housing \& Residence Life Roommate Survey}

The following questions are optional. You may choose to leave them blank. If you choose to answer these items, please circle the option that best applies to you.

Race:

African American

Asian American

Caucasian

Hispanic American

Native American

Other

Sexual Orientation:

Bisexual

Gay/Lesbian

Heterosexual

Questioning
Gender:

Female

Male

Please read the following questions and consider the options you prefer. Be prepared to discuss your preferences with your roommate in order to reach a mutual agreement for a Roommate Contract. Consider multiple options where applicable.

1. I prefer to go to bed between the hours of _ and

2. I sleep best when the room is :

- Completely silent and dark.

- Cool

- Warm

- It doesn't matter, nothing bothers me when I'm asleep.

- Other

3. I prefer to wake up between the hours of and

4. When the alarm goes off I:

- Turn it off \& get up immediately

- Let it go off for several minutes before I wake up

- Hit snooze multiple times

- Other 
5. The time of day I prefer to study is:

- During the morning.

- During the afternoon.

- During the evening.

- Late at night.

6. The atmosphere I prefer when I am studying is:

- Complete silence.

- With the stereo or TV on.

- Alone.

- With Others.

- Outside of the room.

7. I would prefer that visitors, guests, and significant others:

- Be welcome anytime.

- Leave when I am asleep.

- Leave when I am studying.

- Leave when I am asleep or studying unless previously arranged.

- Leave whenever I am in the room.

8. I believe that guests, visitors, and significant others:

- Should not be left alone in the room.

- Can be left alone in the room when previously discussed on an individual basis.

- Should be able to stay in the room without my roommate or myself present.

9. In regard to my personal property, I prefer:

- To share everything.

- To allow my roommate to use specified items without permission.

- To allow my roommate to use items only after asking for permission.

- Not to share anything. 
10. Regarding the appearance of the room, I prefer:

- Usually orderly and clean.

- Sometimes orderly and clean

- No preference.

11. When cleaning the room, I feel that:

- My roommate and I should take turns cleaning the entire room.

- My roommate and I should clean up our own messes.

- My roommate and I should clean up the room together.

12. If my roommate is frustrated or angry with me, I want him or her to :

- Tell me right away and talk about it with me.

- Wait to see if the feelings subside.

- Talk to me about it later.

13. When I am upset, I need:

- To talk about things.

- Space and time to deal with it on my own.

- My own space, unless my feelings are directed toward my roommate

14. I would like to have private time in the room:

- During set times to be arranged.

- To be determined on a situational basis. 


\section{APPENDIX B}

\section{STUDY 1: HEXACO PERSONALITY INVENTORY ITEMS}

\section{Honesty-Humility Items}

Sincerity

9. If this person wants something from a person he/she dislikes, he/she will act very nicely toward that person in order to get it.

103. If this person wants something from someone, he/she will laugh at that person's worst jokes.

55. This person wouldn't pretend to like someone just to get that person to do favors for him/her.

79. This person wouldn't use flattery to get a raise or promotion at work, even if he/she thought it would succeed.

Fairness

15. If this person knew that he/she could never get caught, he/she would be willing to steal a million dollars.

37. This person would be tempted to buy stolen property if he/she were financially tight.

61 . This person would never accept a bribe, even if it were very large.

85 . This person would be tempted to use counterfeit money, if he/she were sure he/she could get away with it.

Greed-Avoidance

21. Having a lot of money is not especially important to this person.

43. This person would like to live in a very expensive, high-class neighborhood.

67. This person would like to be seen driving around in a very expensive car."

91. This person would get a lot of pleasure from owning expensive luxury goods.

Modesty

27. This person is an ordinary person who is no better than others.

49. This person wouldn't want people to treat him/her as though he/she were superior to them.

73. This person thinks that he/she is entitled to more respect than the average person is. ${ }_{*}^{*}$

97. This person wants people to know that he/she is an important person of high status.

\section{Emotionality Items}

\section{Fearfulness}

8. This person would feel afraid if he/she had to travel in bad weather conditions.

102. This person doesn't mind doing jobs that involve dangerous work.

54. When it comes to physical danger, this person is very fearful.

78. Even in an emergency this person wouldn't feel like panicking.

Anxiety

14. This person sometimes can't help worrying about little things.

36. This person worries a lot less than most people do.*

60. This person rarely, if ever, has trouble sleeping due to stress or anxiety. ${ }^{*}$

84. This person gets very anxious when waiting to hear about an important decision. 


\section{Dependence}

20. When this person suffers from a painful experience, he/she needs someone to make him/her feel comfortable.

42. This person can handle difficult situations without needing emotional support from anyone else."

66. Whenever this person feels worried about something, he/she wants to share his/her concern with another person.

90. This person rarely discusses his/her problems with other people."

Sentimentality

26. This person feels like crying when he/she sees other people crying.

48. When someone this person knows well is unhappy, he/she can almost feel that person's pain himself/herself.

72. This person feels strong emotions when someone close to him/her is going away for a long time.

96. This person remains unemotional even in situations where most people get very sentimental."

\section{Extraversion Items}

Social Self-Esteem

7. This person feels reasonably satisfied with himself/herself overall.

31. This person thinks that most people like some aspects of his/her personality.

53. This person feels that he/she is an unpopular person."

77. This person sometimes feels that he/she is a worthless person. ${ }^{*}$

$\underline{\text { Social Boldness }}$

13. This person rarely expresses his/her opinions in group meetings."

35. In social situations, this person is usually the one who makes the first move.

59. When this person is in a group of people, he/she is often the one who speaks on behalf of the group.

83. This person tends to feel quite self-conscious when speaking in front of a group of people.*

Sociability

19. This person avoids making "small talk" with people.

41. This person enjoys having lots of people around to talk with.

65 . This person prefers jobs that involve active social interaction to those that involve working alone.

89. The first thing that this person always does in a new place is to make friends.

Liveliness

25. This person is energetic nearly all the time.

47. On most days, this person feels cheerful and optimistic.

71. People often tell this person that he/she should try to cheer up."

95. Most people are more upbeat and dynamic than this person generally is." 


\section{Agreeableness Items}

Forgiveness

6. This person rarely holds a grudge, even against people who have badly wronged him/her.

30. This person's attitude toward people who have treated him/her badly is "forgive and forget".

52. If someone has cheated this person once, he/she will always feel suspicious of that person.

76. This person finds it hard to fully forgive someone who has done something mean to him/her.

Gentleness

12. People sometimes tell this person that he/she is too critical of others."

34. This person generally accepts people's faults without complaining about them.

58. This person tends to be lenient in judging other people.

82. Even when people make a lot of mistakes, this person rarely says anything negative.

Flexibility

18. People sometimes tell this person that he/she is too stubborn.

40. This person is usually quite flexible in his/her opinions when people disagree with him/her.

64. When people tell this person that he/she is wrong, his/her first reaction is to argue with them.*

88. This person finds it hard to compromise with people when he/she really thinks he/she is right.*

Patience

24. People think of this person as someone who has a quick temper."

46. This person rarely feels anger, even when people treat him/her quite badly.

70. Most people tend to get angry more quickly than this person does.

94. This person finds it hard to keep his/her temper when people insult him/her.

\section{Conscientiousness Items}

Organization

5. This person cleans his/her office or home quite frequently.

29. This person plans ahead and organizes things, to avoid scrambling at the last minute.

51. People often joke with this person about the messiness of his/her room or desk.

75. When working, this person sometimes has difficulties due to being disorganized.

Diligence

11. When working, this person often sets ambitious goals for himself/herself.

33. This person often pushes himself/herself very hard when trying to achieve a goal.

57. Often when this person sets a goal, he/she ends up quitting without having reached it."

81. This person does only the minimum amount of work needed to get by.

Perfectionism

17. This person often checks his/her work over repeatedly to find any mistakes.

39. When working on something, this person doesn't pay much attention to small details.

63. This person always tries to be accurate in his/her work, even at the expense of time.

87. People often call this person a perfectionist. 
Prudence

23. This person makes decisions based on the feeling of the moment rather than on careful thought.*

45. This person makes a lot of mistakes because he/she doesn't think before he/she acts.

69. This person doesn't allow his/her impulses to govern his/her behavior.

93. This person prefers to do whatever comes to mind, rather than stick to a plan.

\section{Openness to Experience}

Aesthetic Appreciation

4. This person would be quite bored by a visit to an art gallery.

28. This person wouldn't spend my time reading a book of poetry.

50. If this person had the opportunity, he/she would like to attend a classical music concert.

74. Sometimes this person likes to just watch the wind as it blows through the trees.

$\underline{\text { Inquisitiveness }}$

10. This person is interested in learning about the history and politics of other countries.

32. This person enjoys looking at maps of different places.

56. This person would be very bored by a book about the history of science and technology.

80. This person never really enjoyed looking through an encyclopedia."

Creativity

16. This person would like a job that requires following a routine rather than being creative.

38. This person would enjoy creating a work of art, such as a novel, a song, or a painting.

62. People have often told this person that he/she has a good imagination.

86. This person doesn't think of himself/herself as the artistic or creative type."

Unconventionality

22. This person thinks that paying attention to radical ideas is a waste of time.

44. This person likes people who have unconventional views.

68. This person thinks of himself/herself as a somewhat eccentric person.

92. This person would find it boring to discuss philosophy.

*indicates that the item was reverse-coded. 


\section{AMERICAN COLLEGE STUDENT ASSOCIATION (ACSA)

\author{
2010/11 Scholarship Instructions
}

PLEASE SUBMIT ONLY ONE APPLICATION.

Completion of items 1 through 4 of the Scholarship Application is mandatory. If the information requested does not apply, enter NA. While most ACSA Scholarships are awarded based on merit, financial need is a consideration in making award decisions. Accordingly, the information you may provide in items 6 and 7 is important if you wish to be considered for the available awards.

\section{ELIGIBILITY - To be eligible, an applicant must satisfy the following requirements:}

1. Be enrolled in or accepted for enrollment in an accredited college or university

2. Be in a position to accept the scholarship in the school year for which it is being awarded

3. Be a full time student

4. Not be receiving full funding for education from another organization (e.g. members of the Armed Services attending US Military Academies, students receiving full reimbursement from an employer)

\section{GENERAL INSTRUCTIONS}

1. Submit only one application package.

a) Complete all items in Sections 1, 2, 3, 4 and 5 of the application form. Sections 6 and 7 are optional

b) Attach all of the application materials listed below

2 All application materials must be completed in ENGLISH

3. No application materials will be returned; no exceptions will be made

4. Do NOT submit photographs of yourself with the application

5. Supplemental materials (e.g. letters of recommendation, writing samples) should NOT be submitted and will NOT be considered

6. All applications must be submitted via email by no later than 11:59 p.m. on January 15, 2010 to scholarship@ACSA.org Late applications will NOT be accepted. You will receive email notification that your application has been received.

\section{DEADLINE}

To be accepted for review, an applicant must submit ALL REQUIRED ITEMS IN ONE EMAIL as listed above by 11:59 p.m. on JANUARY 15, 2010 to scholarship@ACSA.org Scholarship determinations will be made by March 1, 2010.

If you have any questions, please email scholarship@ACSA.org 


\section{APPLICATION MATERIALS}

All information must be provided in ENGLISH. Incomplete applications or application packages will be immediately disqualified from review with no further follow-up. Applications emailed after the applicable deadline will be immediately disqualified from review with no further follow-up. The following items must be submitted:

\section{COMPLETED APPLICATION FORM}

APPLICANT'S STATEMENT - A typewritten statement or essay written by the applicant, NO MORE THAN TWO SINGLE-SIDED 1.5-SPACED, 12-INCH OR LARGER TIMES NEW ROMAN FONT describing:

a) an influential family member or friend, and/or

b) what influenced you to go to college, and/or

c) a hardship you have had to overcome. 


\section{AMERICAN COLLEGE STUDENT ASSOCIATION (ACSA) \\ 2010/11 Scholarship Application Form}

1. ACADEMIC YEAR - Indicate the academic year for which you are applying for scholarship assistance. 2010-11

2. CATEGORY - Indicate below your class status for the academic year indicated.
Freshman
Sophomore
$\square$ Junior
Senior

3. PERSONAL DATA

\begin{tabular}{|c|c|c|c|c|c|c|c|}
\hline \multicolumn{4}{|c|}{ Name (First Middle Last) } & $\begin{array}{l}\text { US Citizen? } \\
\text { Yes }\end{array}$ & \multicolumn{2}{|c|}{$\begin{array}{l}\text { Perm. US } \\
\text { Resident? }\end{array}$} & $\begin{array}{l}\text { Citizenship, if not } \\
\text { US? }\end{array}$ \\
\hline \multicolumn{4}{|c|}{ Social Security No. } & \multicolumn{4}{|c|}{ Alien Registration No. (if applicable) } \\
\hline \multicolumn{4}{|c|}{$\begin{array}{l}\text { Permanent Home Address } \\
157\end{array}$} & \multicolumn{4}{|c|}{ Address at School (if not the same) } \\
\hline City & State & Zip & Phone & City & State & Zip & Phone \\
\hline Philadelphia & PA & & $215-$ & Philadelphia & PA & & $215-$ \\
\hline
\end{tabular}

4. EDUCATION

\begin{tabular}{|l|l|}
\hline $\begin{array}{l}\text { College/University } \\
\text { Temple University } \\
\text { Location (City, State) Philadelphia, PA }\end{array}$ & $\begin{array}{l}\text { Other College or University (if applicable) } \\
\text { Not Applicable } \\
\text { Location (City \& State) }\end{array}$ \\
\hline $\begin{array}{l}\text { Major: } \\
\text { Communications }\end{array}$ & Major: \\
\hline $\begin{array}{l}\text { College GPA (Include basis, e.g. 3.5 out of 4.0) } \\
3.2 \quad \text { out of } 4.0\end{array}$ & $\begin{array}{l}\text { College GPA (Include basis, e.g. 3.5 out of 4.0) } \\
\text { out of }\end{array}$ \\
\hline Degree: B.A. & Degree: \\
\hline
\end{tabular}

\section{NOW MEMBERSHIP}

Are you a current ACSA Member? Yes

\section{SUPPLEMENTAL INFORMATION}

Will you receive funding form an employer, any branch of the armed Services or other organization for tuition, fees and books/supplies? No.

What percentage of total tuition, fees and books/supplies will be paid? $\quad 0 \%$ Will you be obligated to a period of employment or service after graduation? How long? 


\section{OPTIONAL INFORMATION}

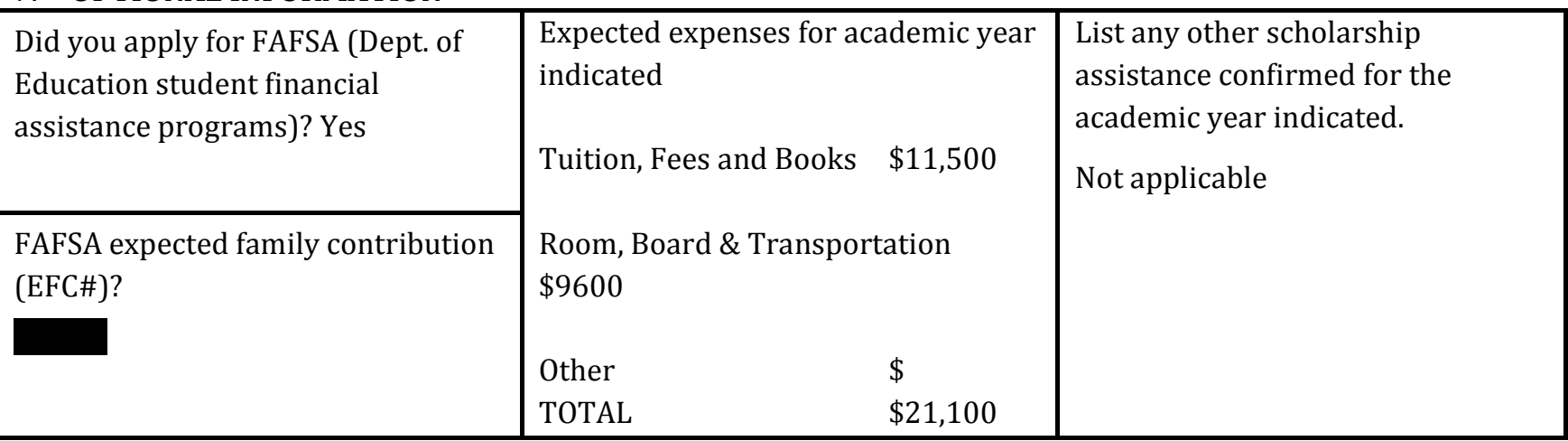

\section{CERTIFICATION}

I believe all the information provided to be true. I hereby apply for an ACSA Scholarship. I further certify that I am not receiving full funding for my education from an employer, any branch of the Armed Services or other organization.

Signature
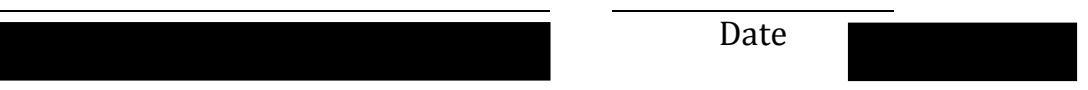

OFFICIAL USE ONLY

\begin{tabular}{|l|l|l|l|l|l|l|l|}
\hline Application & Postmark & Transcript & Good Standing & Ref1 & Ref2 & Essay & $\begin{array}{l}\text { ABET//ABA } \\
\text { App. }\end{array}$ \\
\hline
\end{tabular}




\section{Applicant Statement \\ Lessons from a Missed Opportunity}

A little over a year ago, my family and I were faced with an extremely painful and difficult situation. My grandfather, who was in relatively good health, had been taken to the hospital because of breathing problems related to asthma. However, within the course of two weeks, he was in a coma. The breathing difficulties, which were not originally serious, had worsened, and during his stay in the hospital, he contracted a staphylococcus infection. Unfortunately, by this point he was too weak to fight it. Something that had begun as a slight concern had suddenly turned into a matter of life or death. My family was told that it would be a matter of a few days.

It was like a terrible nightmare to me, completely surreal. When my grandfather had first fallen ill, he and my grandmother were still in their house in Florida where they lived during the winter. Throughout the three weeks that this occurred, I was never able to see him because of the distance between us. This was the first time I would have to experience the death of someone close to me. It was especially painful because everything happened so suddenly and unexpectedly. Before anyone knew what was happening, my loving grandfather was lying in his hospital bed with only a few days left to live.

At first, I was not able to comprehend the seriousness of the situation. I was convinced that my grandfather was going to get better and everything would be back to normal. However, when I realized that things were not as ideal as I wanted them to be, I begged my parents to let me go to Florida to have a chance to say goodbye. My parents decided that I would be better off not seeing my grandpa in his condition, but to this day, I am resentful that they did not let me go.

I have had a tremendously hard time accepting his death because he went from healthy to deceased in a matter of weeks. When my other grandfather passed away a few months ago, I felt that I was able to deal better with his death because he lived closer. This allowed me to digest that his condition was serious just by looking at him. Most importantly, I was able to tell him goodbye and that I loved him.

The fact that I did not get a chance to say goodbye has affected me profoundly, and since my grandfather's death, I realized that I have taken too many things for granted. Losing my grandfather so suddenly has taught me to appreciate everything that I have much more. In the past year, I have become much closer in my personal and family relationships because I realize that the people I care most about will not be around forever. I now take advantage of every moment and everything that I have and have been given because I am determined not to have regrets later in my life. 


\section{APPENDIX D}

STUDY 2: SCHOLARSHIP APPLICATION EVALUATION QUESTIONS

1. How closely did the applicant follow the directions for completing the scholarship application?

2. Rate the overall quality of the applicant's scholarship application.

3. Rate the writing clarity of the applicant's personal statement.

4. Rate the organization of the applicant's personal statement.

5. Rate the grammar and spelling of the applicant's personal statement.

6. How likely do you think it is that this scholarship will be awarded to the applicant?

Note: All questions were answered on a 6-pointing rating scale ranging from 0 to 5. 


\section{APPENDIX E}

\section{STUDY 2: STEREOTYPICALITY RATINGS USED IN PILOT STUDY}

Thank you very much for agreeing to complete this short measure. I am interested in your perceptions of stereotypes and stereotype knowledge. I am most interested in your knowledge of the content of the cultural stereotype NOT your personal beliefs. Please circle the number that best describes your answer.

Compared to women in general, how stereotypical is the trait feminine of African American people in general?

$\begin{array}{llllllll} & 0 & 1 & 2 & 3 & 4 & 5 & 6 \\ \text { (Not stereotypical) } & & & & & & & \text { (Very stereotypical) }\end{array}$

Compared to women in general, how stereotypical is the trait poor of African American people in general?

(Not stereotypical)

$\begin{array}{lllllll}0 & 1 & 2 & 3 & 4 & 5 & 6\end{array}$

(Very stereotypical)

Compared to women in general, how stereotypical is the trait strong of African American people in general?

(Not stereotypical)

$\begin{array}{lllllll}0 & 1 & 2 & 3 & 4 & 5 & 6\end{array}$

(Very stereotypical)

Compared to women in general, how stereotypical is the trait emotional of African American people in general?

$\begin{array}{llllllll} & 0 & 1 & 2 & 3 & 4 & 5 & 6 \\ \text { (Not stereotypical) } & & & & & & & \text { (Very stereotypical) }\end{array}$

Compared to women in general, how stereotypical is the trait aggressive of African American people in general?

(Not stereotypical)

$\begin{array}{lllllll}0 & 1 & 2 & 3 & 4 & 5 & 6\end{array}$

(Very stereotypical) 
Compared to women in general, how stereotypical is the trait loud of African American people in general?

(Not stereotypical)

$$
\begin{array}{lllllll}
0 & 1 & 2 & 3 & 4 & 5 & 6
\end{array}
$$

(Very stereotypical)

Compared to women in general, how stereotypical is the trait nurturing of African American in general?

$\begin{array}{llllllll} & 0 & 1 & 2 & 3 & 4 & 5 & \begin{array}{l}6 \\ \text { (Not stereotypical) }\end{array} \\ & & & & & & \text { (Very stereotypical) }\end{array}$

Compared to women in general, how stereotypical is the trait criminal of African American people in general?

$\begin{array}{llllllll} & 0 & 1 & 2 & 3 & 4 & 5 & 6 \\ \text { (Not stereotypical) } & & & & & & & \text { (Very stereotypical) }\end{array}$

Compared to women in general, how stereotypical is the trait animated of African American people in general?

$\begin{array}{llllllll} & 0 & 1 & 2 & 3 & 4 & 5 & 6 \\ \text { (Not stereotypical) } & & & & & & & \text { (Very stereotypical) }\end{array}$

Compared to women in general, how stereotypical is the trait pretty of African American people in general?

(Not stereotypical)

$\begin{array}{lllllll}0 & 1 & 2 & 3 & 4 & 5 & 6\end{array}$

(Very stereotypical)

Compared to women in general, how stereotypical is the trait uneducated of African American people in general?

$\begin{array}{llllllll} & 0 & 1 & 2 & 3 & 4 & 5 & 6 \\ \text { (Not stereotypical) } & & & & & & & \text { (Very stereotypical) }\end{array}$

Compared to women in general, how stereotypical is the trait promiscuous of African American people in general?

(Not stereotypical)

$\begin{array}{lllllll}0 & 1 & 2 & 3 & 4 & 5 & 6\end{array}$

(Very stereotypical) 
Compared to women in general, how stereotypical is the trait motherly of African American people in general?

(Not stereotypical)

$\begin{array}{lllllll}0 & 1 & 2 & 3 & 4 & 5 & 6\end{array}$

Compared to women in general, how stereotypical is the trait lazy of African American people in general?

(Not stereotypical)

$$
\begin{array}{lllllll}
0 & 1 & 2 & 3 & 4 & 5 & 6
\end{array}
$$

(Very stereotypical)

Compared to women in general, how stereotypical is the trait overweight or large of African American people in general?

$\begin{array}{llllllll} & 0 & 1 & 2 & 3 & 4 & 5 & 6 \\ \text { (Not stereotypical) } & & & & & & & \text { (Very stereotypical) }\end{array}$

Compared to women in general, how stereotypical is the trait romantic of African American people in general?

$\begin{array}{llllllll} & 0 & 1 & 2 & 3 & 4 & 5 & 6 \\ \text { (Not stereotypical) } & & & & & & & \text { (Very stereotypical) }\end{array}$

Compared to women in general, how stereotypical is the trait proud of African American people in general?

(Not stereotypical)

$\begin{array}{lllllll}0 & 1 & 2 & 3 & 4 & 5 & 6\end{array}$

(Very stereotypical)

Compared to women in general, how stereotypical is the trait athletic of African American people in general?

$\begin{array}{llllllll} & 0 & 1 & 2 & 3 & 4 & 5 & 6 \\ \text { (Not stereotypical) } & & & & & & & \text { (Very stereotypical) }\end{array}$

Compared to women in general, how stereotypical is the trait unfeminine of African American people in general?

(Not stereotypical)

$\begin{array}{lllllll}0 & 1 & 2 & 3 & 4 & 5 & 6\end{array}$

(Very stereotypical) 
Compared to women in general, how stereotypical is the trait independent of African American people in general?

(Not stereotypical)

$\begin{array}{lllllll}0 & 1 & 2 & 3 & 4 & 5 & 6\end{array}$

Compared to women in general, how stereotypical is the trait rhythmic of African American people in general?

$\begin{array}{llllllll} & 0 & 1 & 2 & 3 & 4 & 5 & 6 \\ \text { (Not stereotypical) } & & & & & & & \text { (Very stereotypical) }\end{array}$

Compared to women in general, how stereotypical is the trait unattractive of African American people in general?

$\begin{array}{llllllll} & 0 & 1 & 2 & 3 & 4 & 5 & 6 \\ \text { (Not stereotypical) } & & & & & & & \text { (Very stereotypical) }\end{array}$

Compared to women in general, how stereotypical is the trait religious of African American people in general?

$\begin{array}{llllllll} & 0 & 1 & 2 & 3 & 4 & 5 & 6 \\ \text { (Not stereotypical) } & & & & & & & \text { (Very stereotypical) }\end{array}$

Compared to women in general, how stereotypical is the trait curvy of African American people in general?

(Not stereotypical)

$\begin{array}{lllllll}0 & 1 & 2 & 3 & 4 & 5 & 6\end{array}$

(Very stereotypical)

Compared to women in general, how stereotypical is the trait matriarch of African American people in general?

$\begin{array}{llllllll} & 0 & 1 & 2 & 3 & 4 & 5 & 6 \\ \text { (Not stereotypical) } & & & & & & & \text { (Very stereotypical) }\end{array}$

Compared to women in general, how stereotypical is the trait rude of African American people in general?

(Not stereotypical)

$\begin{array}{lllllll}0 & 1 & 2 & 3 & 4 & 5 & 6 \\ & & & & & \end{array}$


Compared to women in general, how stereotypical is the trait family-oriented of African American people in general?

$\begin{array}{llllllll} & 0 & 1 & 2 & 3 & 4 & 5 & 6 \\ \text { (Not stereotypical) } & & & & & & & \text { (Very stereotypical) }\end{array}$

Compared to women in general, how stereotypical is the trait obnoxious of African American people in general?

$\begin{array}{llllllll} & 0 & 1 & 2 & 3 & 4 & 5 & 6 \\ \text { (Not stereotypical) } & & & & & & & \text { (Very stereotypical) }\end{array}$

